\title{
Mapping the field: a bibliometric analysis of the literature on university-industry collaborations
}

\author{
Igors Skute $^{1}$ (D) Kasia Zalewska-Kurek $^{1} \cdot$ Isabella Hatak $^{1} \cdot$ \\ Petra de Weerd-Nederhof ${ }^{1}$
}

Published online: 7 November 2017

(C) The Author(s) 2017. This article is an open access publication

\begin{abstract}
The substantial acknowledgement of university-industry (U-I) collaborations as promotor of economic progress, innovativeness and competitiveness fostered a continuous research engagement. At the same time, the U-I literature experienced a notable increase in the past decade, transforming into a multi-faceted and ambiguous research field, characterised by highly complex interlinks. The recent transformation hinders a comprehensive understanding of the latest developments in research directions and their clear delineation. Therefore, the purpose of this bibliometric literature review is to examine the evolution of the field and identify the primary emerging patterns. This paper employs co-citation analysis and bibliographic coupling techniques to analyse the U-I publications dataset. The findings indicate that the U-I collaborations research can be systematically clustered, resulting in an interconnected ecosystem consisting of three levels: individual, organisational and institutional, respectively. Thus, this review presents the immense contribution that the analysis of U-I collaborations makes to various research streams. Building on these findings and employing qualitative content analysis on the clustered publications, the paper develops a research agenda that encourages future investigations of previously overlooked features of U-I collaborations in general, and their role across levels of analysis, contexts and stages of the collaboration process in particular.
\end{abstract}

Keywords University-industry $\cdot$ Bibliometrics $\cdot$ Co-citation analysis · Bibliographic coupling · Academic entrepreneurship - Technology transfer $\cdot$ Knowledge transfer

JEL Classification $\mathrm{M} 13 \cdot \mathrm{O} 31 \cdot \mathrm{O} 32$

Igors Skute

i.skute@utwente.nl

1 Netherlands Institute for Knowledge-Intensive Entrepreneurship, University of Twente, P.O. Box 217, 7500 AE Enschede, The Netherlands 


\section{Introduction}

In recent years, university-industry (U-I) collaborations have garnered substantial interest as a source for knowledge production and new technological advancements, fostering the economic and innovative competitiveness of regions (Bishop et al. 2011; D'Este et al. 2013; Rasmussen and Wright 2015). This interest largely proceeds from three sets of arguments. The first argument relates to quantity-industrial partners increasingly engage in collaborative activities with academic institutions to source the cutting edge R\&D insights and leverage their research and product development capabilities (Perkmann et al. 2011). At the same time, becoming more ambidextrous, universities actively engage in the commercialisation of research results and technological advancements after research activities (D'Este and Perkmann 2011; Perkmann et al. 2013; Villani et al. 2017). Second, related to quality, both university and industry collaboration partners encounter challenges in successfully managing their inter-organisational innovation processes and the associated relational and institutional dependencies (Bozeman et al. 2013; Van Looy et al. 2011; Wirsich et al. 2016). Third, policy makers increasingly hail U-I collaborations as a tool to address economic and societal challenges by novel means (Ponds et al. 2010; Lehmann and Menter 2016).

Thus, understanding the mechanisms that foster and hinder U-I collaborations has also become a crucial challenge for scholars (D'Este et al. 2013; Maietta 2015; Rasmussen and Wright 2015). Broadly, U-I collaborations refer to partnerships between one or several academic or research institutions and one or several firms operating in industrial markets focused on collaborative R\&D activities (Bozeman et al. 2013; Perkmann and Walsh 2007; Petruzzelli 2011). The importance of the research area is evidenced by the fast-growing number of scholarly publications addressing the following: characteristics and motives of individuals engaged in the commercialisation of research, both from academia and industry, and their effects; characteristics and motives of the organisations involved in collaborative R\&D activities, and their effects; and characteristics and developments of regional policy measures targeted to foster U-I collaborations (Carayannis and Campbell 2012; Laursen et al. 2011; Link 2015; Perkmann et al. 2013). Prior research highlights a broad variety of elements shaping the U-I collaboration process and identifies several predictors of the scientific and economic impact of joint research activities.

Consequently, the current state of knowledge, on the one hand, can be seen as relatively fragmented by following distinct directions of fundamental research perspectives. Conversely, the scope of the U-I collaborations literature is continuously extended, evidenced by increasing research on complex interconnections among diverse elements of U-I collaborations (Link 2015). Thus, the current body of U-I knowledge has recently been transformed into a complex, multi-faceted field with many interlinkages that exacerbate a far-reaching and robust interpretation of findings due to the application of different theoretical perspectives and models (Perkmann et al. 2013; Petruzzelli 2011; Teixeira and Mota 2012). Specifically, U-I research appears to not coherently establish connections between previously adopted theoretical understandings and empirical models, hindering the visibility of clear directions for coherent future research. Therefore, U-I researchers run the risk of duplicating empirical findings while leaving knowledge gaps in other areas (Delgado García et al. 2015; Gerbin and Drnovsek 2016). Consequently, a coherent analysis of the evolution of the U-I collaboration research and a reflection against current thematic areas and emerging patterns are needed (Diez-Vial and Montoro-Sanchez 2017; Minguillo et al. 2015; Teixeira and Mota 2012). 
To address the challenges indicated above, we conduct a quantitative bibliometric analysis of 435 peer-reviewed articles, using co-citation analysis and bibliographic coupling techniques. Up to now, quantitative review approaches in the context of U-I studies are limited, especially when it comes to capturing the field's latest developments (for calls resolving this gap, see e.g., Teixeira and Mota 2012; Meyer et al. 2014; Davey et al. 2016). This limitation is surprising, as narrative reviews can include sampling, measurement, stochastic, and external validity issues and generally do not allow to quantify the relationships (Schmidt and Hunter 2004). Furthermore, narrative reviews frequently incorporate various normative and cognitive biases of the researcher (Rosenbusch et al. 2011). In turn, by employing a quantitative approach to our literature analysis, we unravel the scientific roots of the U-I research and identify current thematic areas and emerging patterns in the field. Additionally, by conducting a qualitative content analysis, based on the identified articles, we generate nuanced insights into relevant future research directions.

The results of the co-citation analysis imply that the U-I research field is based on four thematic clusters focused on the following: (1) the distance perspective and the impact of partner complementarity, (2) the antecedents and consequences of academic entrepreneurship, (3) the ecosystem perspective regarding the governance mechanisms and policy developments and (4) the efficiency of the available interaction channels and knowledge transfer. In turn, the results of bibliographic coupling suggest six current and emerging thematic clusters. While three themes are overlapping with the findings of the cocitation analysis, namely the ecosystem perspective (cluster 1), academic entrepreneurship perspective (cluster 3), and distance perspective (cluster 4), we uncovered three additional inter-related themes: the social relations perspective (cluster 2) addressing the relationship development among individuals and firms, interaction process and knowledge transfer perspective outlining the dynamics and key elements of the U-I collaborations, and policy implications perspective (cluster 6) highlighting the impact of regional policy developments.

This paper makes the following contributions: First, this study uncovers the evolution of the U-I collaboration concept by comparing its foundations with current thematic areas and emerging patterns. This paper consolidates the insights generated by $\mathrm{U}-\mathrm{I}$ researchers in the past years, thus providing a comprehensive reflection of the research field. Second, by performing a content analysis of identified thematic areas, this study advances a multilayered and inter-connected research agenda encouraging future investigations of previously understudied features and mechanisms of U-I collaborations on individual, organisational and institutional levels in general, and their role in various contexts and stages of the collaboration process in particular.

The article is structured as follows. In the following section, we explain the research design and methods employed. Then, the main results of the co-citation analysis and bibliographic coupling are presented. Furthermore, we discuss the main implications for academics and policy makers, while defining the emerging patterns in the field and presenting future research directions. Finally, limitations of this study are discussed.

\section{Research design}

The articles for this review were retrieved from the Thomson Reuters Web of Science database. This database is recognised to cover a broad range of relevant journals and peerreviewed articles of high quality. While we acknowledge the availability of various other 
databases, we act in accordance with the methodological approach of previous research (see e.g., Meyer et al. 2014); in addition, as we focus mainly on investigating patterns of indicators, this restriction can be accepted. We use 'university industry' as the keyword for searching titles, abstracts and/or keywords while allowing for variations of term spelling (e.g., 'university-industry', 'university/industry' etc.). This keyword combination allows to grasp the U-I literature scope at a broad level and minimises the risk of including false positive items that do not compliment the actual thematic literature, potentially leading to misleading interpretations of the state of knowledge (Kovács et al. 2015). We restricted the search to document type - that is, articles - in the Web of Science database and to the literature published in the period of 2011-2016 (incl.) to complement previous research and to study the latest and emerging developments in the field. This search process resulted in a final sample of 435 articles in total, referring to 3102 citations and 14,705 references. To avoid false positive items in the dataset, all articles that formed a corpus for bibliographic coupling and that provided the basis for a set of references used for co-citation analysis were checked for the inclusion of the 'university industry' keyword or its variation in title, abstract and/or keywords.

To analyse publication scientific mapping patterns and to evaluate the similarity of U-I literature themes, co-citation analysis and bibliographic coupling techniques were applied (Boyack and Klavans 2010; Kessler 1963; Small 1973). Bibliographic coupling focuses on matching articles in the dataset based on shared references. In turn, co-citation analysis matches articles in the dataset that are jointly cited by another article. Due to its nature, cocitation analysis is based on cited articles and therefore is suited for examining the development of the literature from its roots, while bibliographic coupling is based on citing articles and hence is more applicable to identify the current state of the literature and the emerging patterns (see e.g., Boyack and Klavans 2010; Meyer et al. 2014; Kovács et al. 2015).

Thematic clusters were developed and visualised based on normalised relatedness measures. An association strength measure was chosen as appropriate for normalising cooccurrence data, in accordance with the methodological approach adopted by previous studies (Kovács et al. 2015; van Eck and Waltman 2009; Waltman et al. 2010). A detailed methodological overview including calculations of the association strength measure and comparison to other well-known measures is provided in Van Eck and Waltman (2009) and Waltman et al. (2010). Clustered bibliometric networks were constructed by adopting the visualisation of similarities (VOS) approach using an optimised algorithm of VOSviewer 1.6.5 (van Eck and Waltman 2007, 2010).

Additionally, qualitative content analysis of the publications based on the clustering results was used. The identified clusters were labelled accordingly by performing the term frequency count and analysing the content of titles, abstracts and keywords of the clustered publications. Subsequently, the 20 most cited articles with the highest link strength in each cluster were qualitatively analysed by the authors to reveal future research suggestions by manually scanning and coding relevant paragraphs of the full text publications using Atlas.ti software. To ensure not only breadth, but also depth of future research opportunities, the discussion about future research avenues was enriched with additional literature. 


\section{Results}

\subsection{Co-citation analysis results}

The results of co-citation analysis are illustrated in Fig. 1. The visualised bibliometric network represents four interconnected clusters with unique labels that are based on the cited references from the initial dataset of 435 publications. The original dataset consisting of 435 articles published in the period of 2011-2016 refers to 14,705 references that are standardised to the same format for further analysis. However, in the co-citation analysis, we include publications with at least ten citations to ensure an analysis of an essential literature, avoiding the potential risk of overly complicating the interpretation (Kovács et al. 2015). This restriction leads to 245 references meeting the threshold. In accordance with the goal to examine the evolution of the U-I research field and the corpus of references used for co-citation analysis, we also include the cited literature published before 2011.

Each scientific publication depicted in the visualised bibliometric network represents a unique cited reference that is clustered based on the likelihood to be cited in combination with other items. Items that are assigned to the same cluster share a higher probability to be cited together by another publication. Colours indicate the clusters and articles belonging to them. Moreover, a specific weight is assigned to each item based on a total link strength of the publication and the number of citations it has received. For a better overview, publications with higher total link strength are visualised in a larger size (van Eck and Waltman 2010).

Based on the results of the co-citation analysis, we retrieved the information necessary to conduct an additional examination of the journals interested in publishing U-I research

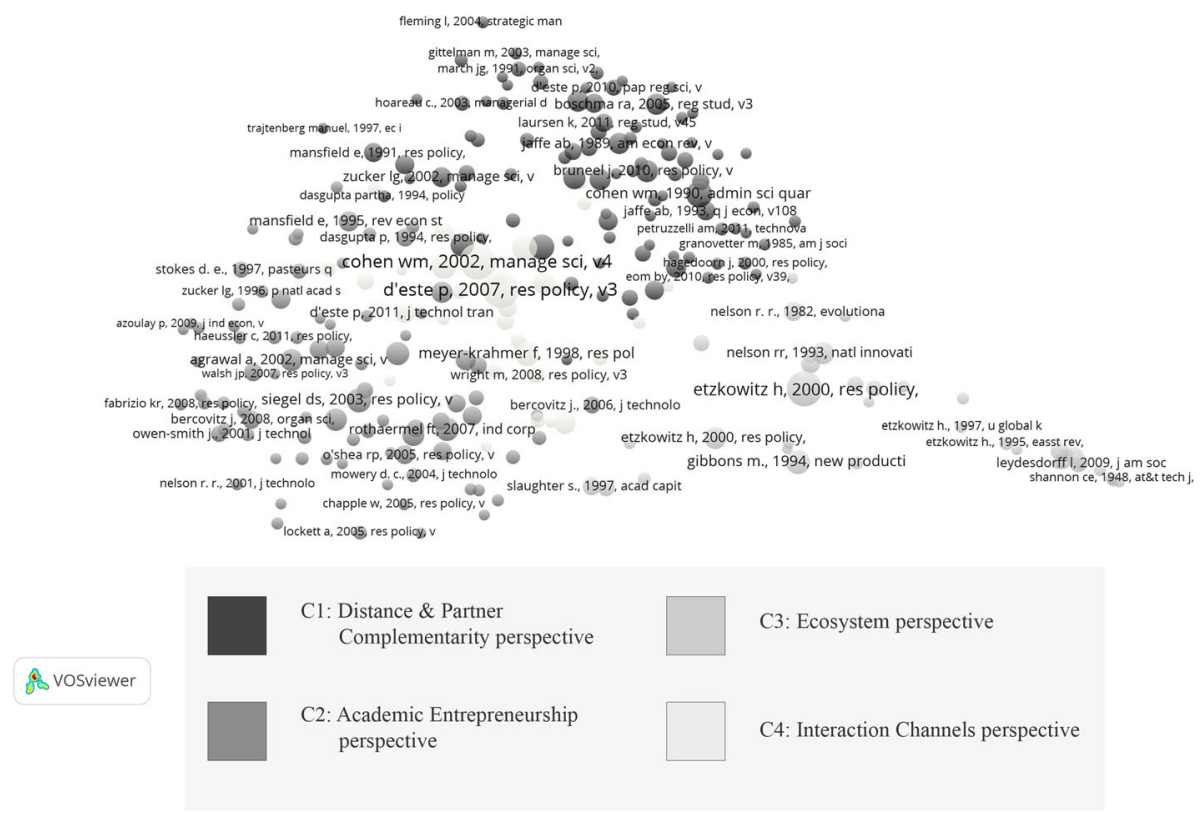

Fig. 1 A visualised bibliometric network of clustered articles included in the dataset, using co-citation analysis technique 
and the keywords associated with the analysed publications. The results show that the three leading peer-reviewed journals (Fig. 2) that published the highest number of contributions to the U-I literature (period of 2011-2016) are Research Policy (95 publications), followed by the Journal of Technology Transfer (16 publications) and Management Science (9 publications). Moreover, we measured the term frequency of keywords assigned to the journals to examine the most important keywords in the cited references of the initial U-I literature dataset (Fig. 3).

Based on the visualisation of similarities (VOS) approach and the co-citation analysis technique, the current body of U-I research was divided into four thematic clusters and labelled based on the authors' independent content analysis. In addition, it needs to be acknowledged that - while the authors' attempted to define clusters in a manner that would reflect the entire scope of the U-I literature-the foci of the articles included in the analyses are of a broad variety; therefore, certain elements cannot be fully elaborated on.

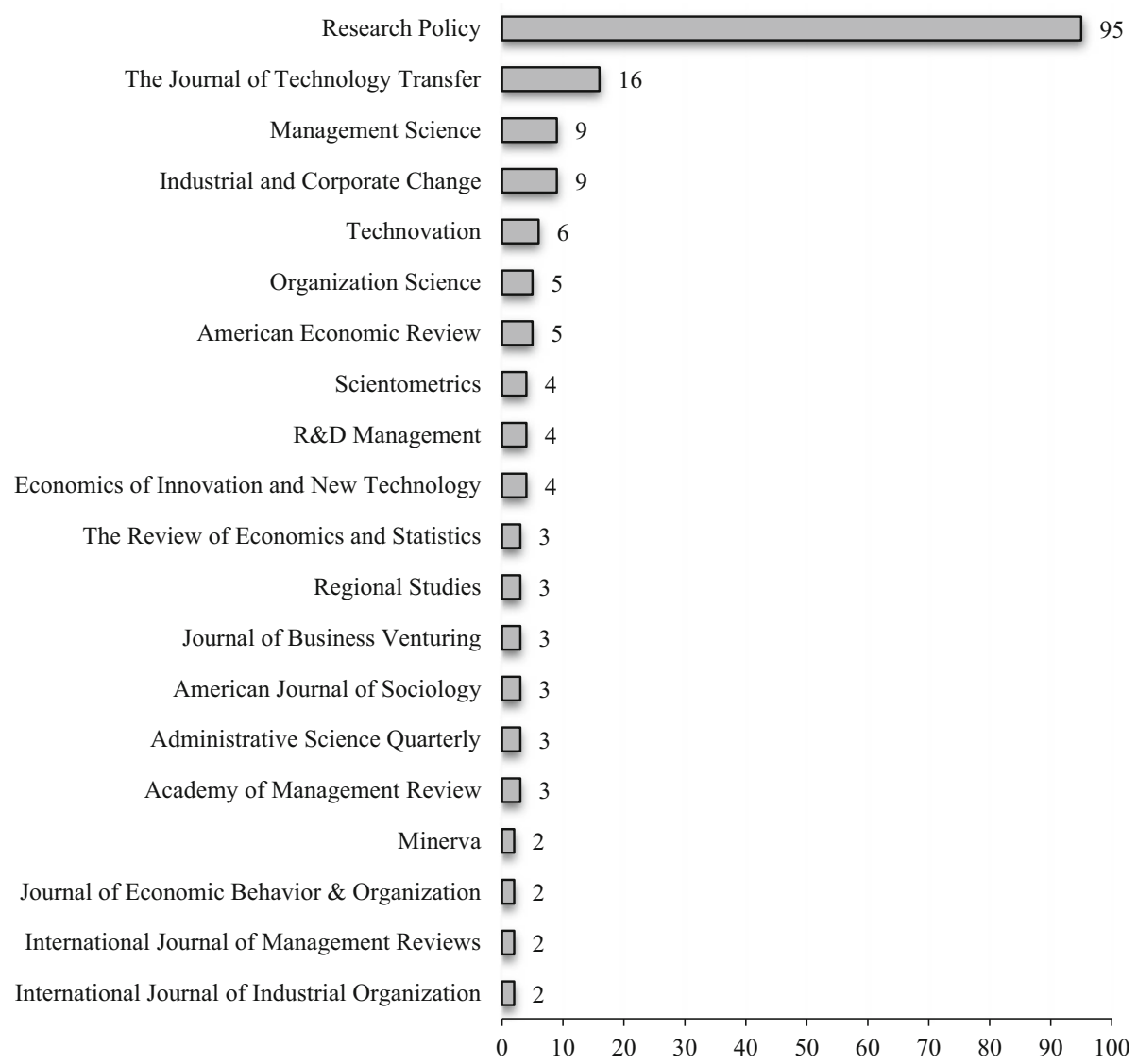

Fig. 2 Overview of the most popular journals, based on the number of scientific publications, using the cocitation analysis technique 


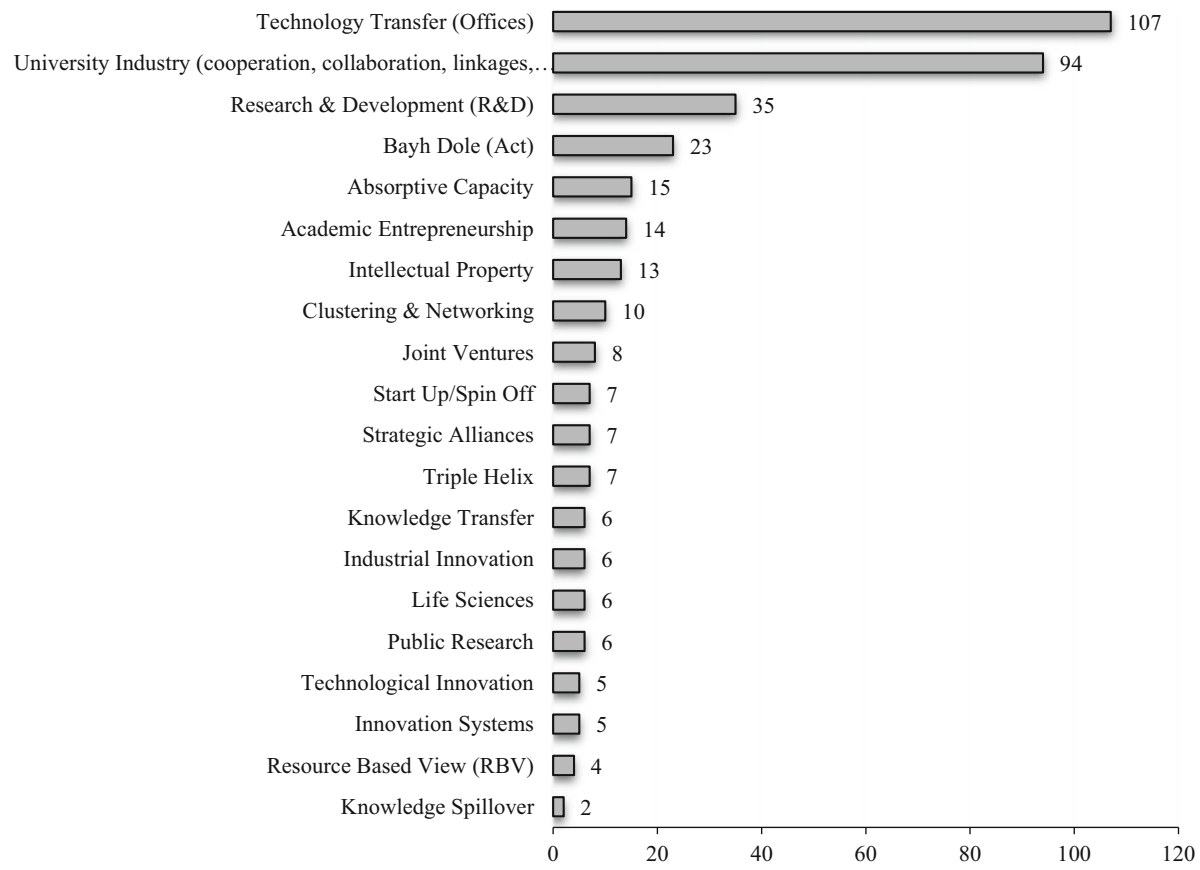

Fig. 3 Overview of the most frequent keywords assigned to the articles, using the co-citation analysis technique

\subsubsection{Cluster 1: Distance and partner complementarity perspective}

Research belonging to this cluster is focused on understanding the impact of U-I partner distance and partner complementarity on their potential to foster innovation and regional economic development by means of joint scientific and technological advancements. Specifically, this cluster explores the role of partner capabilities critical to efficiently acquire, assimilate, transform and effectively exploit knowledge and resources shared and generated within U-I and other R\&D collaborations (Cohen and Levinthal 1989; Zahra and George 2002). A pivotal factor determining the likelihood to successfully exploit and translate the partner complementary potential into innovative products, services or processes is the level of absorptive capacity possessed by the actors (Cohen and Levinthal 1990; Tether and Tajar 2008). Prior research has devoted major resources to understanding the dimensions of absorptive capacity and the dynamics of research cooperation among diverse research partners (Santoro and Chakrabarti 2002). Additionally, this cluster explores the role of partner proximity for innovation outcomes (Jaffe 1989; Jaffe et al. 1993; Salter and Martin 2001). For example, seminal work focused on geographical closeness between the partners and regional knowledge spillovers as a determinant of patent citations and innovation performance (Jaffe et al. 1993; Anselin et al. 1997). Further research examined additional types of partner proximity, such as partner cognitive distance, and related concepts, such as social capital and networking capabilities (Tether and Tajar 2008; Ponds et al. 2010). Thus, this cluster assembles the articles that investigate the relationship between partner (a) distance and degree of complementarity and (b) their capability to increase the quality of interactions, patent generation and regional economic 
development. Research articles also extend to other directions, for example, providing a critical outlook on the time lag between research activities and industrialisation/commercialisation of joint technological advancements (Fleming and Sorenson 2004; Mansfield 1991).

\subsubsection{Cluster 2: Academic entrepreneurship perspective}

This cluster centres on the analysis of university evolution from traditionally research- and education-oriented institutions towards the development of a multi-faceted system of academic entrepreneurship. Following the Bayh-Dole Act, academic entrepreneurship has received increasing attention from scholars and practitioners (Mowery et al. 2001). Correspondingly, research that belongs to this cluster is focused on understanding how, and with what effects opportunities to engage in academic entrepreneurship are discovered, evaluated and exploited, and by whom. The first sub-stream of this cluster addresses the role of characteristics of individual researchers and their universities for engaging in entrepreneurial activities, such as quality and size of the faculty, previous experiences, commercial and research orientation, and funding and commercial capabilities of the researchers and their universities (Mansfield 1995; Etzkowitz 2003a; O'Shea et al. 2005; Bercovitz and Feldman 2008). A related topic of this sub-stream investigates incentives and barriers affecting the engagement of researchers and universities in entrepreneurial activities (Siegel et al. 2003).

The second sub-stream addresses the role of technology transfer office (TTO) as a mechanism to successfully commercialise research results, and their related role in interaction channels as a facilitator of knowledge and technology transfer between the U-I collaboration partners (Bozeman 2000; Thursby and Thursby 2002). Moreover, research articles of this cluster explored which combinations of these factors and mechanisms ensure an increase of the academic entrepreneurship output by means of academic spinoffs, patents and other types of research licensing (Lockett and Wright 2005; Zucker and Darby 1996). Finally, institutional and policy settings also have been considered as relevant contingencies within academic entrepreneurship (Di Gregorio and Shane 2003; Van Looy et al. 2004; Debackere and Veugelers 2005).

\subsubsection{Cluster 3: Ecosystem perspective}

With the increasing recognition of U-I collaborations as a catalyst for regional and national economic development, the interaction between university, industry and government has attracted notable interest in research (Park et al. 2005). This cluster addresses the roles of the actors embedded in this ecosystem and the sub-dynamics of economic exchange, scientific and technological innovation, and institutional control within the Triple Helix model (Leydesdorff and Fritsch 2006). Within the ecosystem perspective, by developing contractual agreements with industry partners to conduct research in particular areas and exploit the economic potential, university representatives exercise some of the functions of research administrators in private business (Etzkowitz 1984). In turn, in certain circumstances, the government acts as a public entrepreneur and venture capitalist in addition to its traditional regulatory activities; therefore, the research in this cluster is focused on understanding the hybridisation and interconnections among the Triple Helix actors, as well as the knowledge producers and users (Etzkowitz 2003b). Additionally, publications in this cluster analyse the evolution of the university as a facilitator of knowledge production that follows government-supported initiatives designed together with industry to 
facilitate the development of an ecosystem for new firm formation and regional growth (Etzkowitz and Leydesdorff 2000; Etzkowitz and Klofsten 2005). Similarly, this cluster addresses the regional and national policy developments supporting the U-I interactions. An important issue remains regarding understanding differences in Triple Helix configurations across different sectors (e.g., mid-tech and high-tech) and in different regions with diverse institutional characteristics (Lengyel and Leydesdorff 2011; Leydesdorff and Fritsch 2006; Leydesdorff and Sun 2009).

\subsubsection{Cluster 4: Interaction channels perspective}

Research belonging to this cluster focuses on the variety of interaction channels between the involved parties of U-I partnerships and the associated determinants. The central element of this cluster is the identification and characterisation of distinct interaction channels and knowledge transfer mechanisms, ranging from scientific publications and published reports, public conferences and meetings, licencing and patenting and to contract research and consultancy (Cohen et al. 2002; Wright et al. 2008). In addition to identifying types of interaction channels and knowledge transfer mechanisms, research belonging to this cluster provides an in-depth analysis of the incentives and the associated determinants regarding the choice towards a specific channel (Geuna and Muscio 2009). Bekkers and Bodas Freitas (2008) suggest that the characteristics of the transferred knowledge, the characteristics of researchers involved, and the environment in which knowledge is produced and exploited determine the selection of a specific interaction channel. Subsequently, a related sub-stream examines the outcomes associated with the implementation of distinct interaction channels, such as the interaction quality and the associated risks and benefits within U-I partnerships (Arza 2010; Dutrénit et al. 2010). Nevertheless, it remains an important challenge to nuance the effects of distinct interaction channels by considering short versus long-term goals, as well as acknowledge the role of the context by exploring outcomes across different sectors and collaborative projects with varying intensity of interaction (Schartinger et al. 2002). An interesting sub-stream of research explores alternative forms of interaction channels by means of attracting talent to the local economy and collaborating with local industry by offering formal and informal technical support (Bramwell and Wolfe 2008). Finally, a less investigated but promising research direction addresses the antecedents and consequences of collaborative portfolio management in terms of the scope of activities and the types of firms with which they interact (Wright et al. 2008).

Additionally, we summarised the key statistical details of the identified clusters (Table 1). The statistical comparison indicates different evolution patterns of the identified thematic clusters and their relative importance for researchers. While the distance and partner complementarity perspective (Cluster 1) holds the most dominant position in terms of the total number of publications and the number of citations, other clusters have varied impacts. The academic entrepreneurship perspective (Cluster 2) has a similar number of publications to the distance and partner complementarity perspective; nevertheless, the total and average numbers of citations indicate that it covers a smaller number of seminal works that would shape the U-I research field. However, compared to the ecosystem (Cluster 3) and the interaction channels clusters (Cluster 4), the academic entrepreneurship perspective (Cluster 2) appears to possess a slightly higher impact, as it is also the second most recent cluster (13.81 years avg. existence). Simultaneously, the interactive channels perspective (Cluster 4 ) is the youngest cluster in terms of existence in years of publications, on average (9.91), suggesting a notable development of the interaction channels 
Table 1 Key statistical indicators of the clustered publications, based on the co-citation analysis technique

\begin{tabular}{|c|c|c|c|c|c|}
\hline & $\begin{array}{l}\text { Number of } \\
\text { publications }\end{array}$ & $\begin{array}{l}\text { Total } \\
\text { citations } \\
\text { per cluster }\end{array}$ & $\begin{array}{l}\text { Average } \\
\text { citations per } \\
\text { publication }\end{array}$ & $\begin{array}{l}\text { Average existence } \\
\text { of publications (in } \\
\text { years) }\end{array}$ & $\begin{array}{l}\text { Three most cited } \\
\text { articles } \\
\text { (citations) }\end{array}$ \\
\hline $\begin{array}{l}\mathrm{C} 1 \text { : Distance and } \\
\text { partner } \\
\text { complementarity } \\
\text { perspective }\end{array}$ & 92 & 72,883 & 792.21 & 17.36 & $\begin{array}{l}\text { Eisenhardt } \\
\text { (1989); 10,490 } \\
\text { Cohen and } \\
\text { Levinthal } \\
\text { (1990); } 9399 \\
\text { Granovetter } \\
\text { (1985); } 8174\end{array}$ \\
\hline $\begin{array}{l}\text { C2: Academic } \\
\text { entrepreneurship } \\
\text { perspective }\end{array}$ & 84 & 11,359 & 135.23 & 13.81 & $\begin{array}{l}\text { Mowery et al. } \\
\quad(2001) ; 452 \\
\text { Siegel et al. } \\
\quad(2003) ; 452 \\
\text { Henderson et al. } \\
\quad(1998) ; 440\end{array}$ \\
\hline $\begin{array}{l}\text { C3: Ecosystem } \\
\text { perspective }\end{array}$ & 36 & 2973 & 82.58 & 19.81 & $\begin{array}{l}\text { Etzkowitz and } \\
\text { Leydesdorff } \\
\text { (2000); } 1324 \\
\text { Etzkowitz and } \\
\text { Leydesdorff } \\
\text { (2000); } 535 \\
\text { Etzkowitz } \\
\text { (2003b); } 245\end{array}$ \\
\hline $\begin{array}{l}\text { C4: Interaction } \\
\quad \text { channels perspective }\end{array}$ & 33 & 3539 & 107.24 & 9.91 & $\begin{array}{l}\text { Cohen et al. } \\
\text { (2002); } 685 \\
\text { Klevorick et al. } \\
\text { (1995); } 436 \\
\text { D'Este and Patel } \\
\text { (2007); } 330\end{array}$ \\
\hline
\end{tabular}

research in the past decade. Both the research on distance and partner complementarity (Cluster 1) and ecosystem perspectives (Cluster 3) share a long history of evolution, significantly shaping the U-I research development patterns and providing a solid foundation for current and future advancements.

\subsection{Bibliographic coupling results}

The results of bibliographic coupling that outline the current research perspectives in the U-I research field are illustrated in Fig. 4. Similar methodological steps are applied to the interpretation of bibliographic coupling results. Nevertheless, the implemented differences should be clearly outlined. We apply no restrictions concerning the number of citations to grasp the entire dataset with research articles published from 2011 to 2016. As noted previously, this choice has been made to complement the previous research and develop new insights based on previous reviews. From a total sample of 435 articles included in the analysis, 402 articles were clustered and included in the illustrated bibliographic network. Excluded articles represent a sample of publications with no shared references with other articles in the dataset and therefore cannot be connected. In addition, two clusters were 


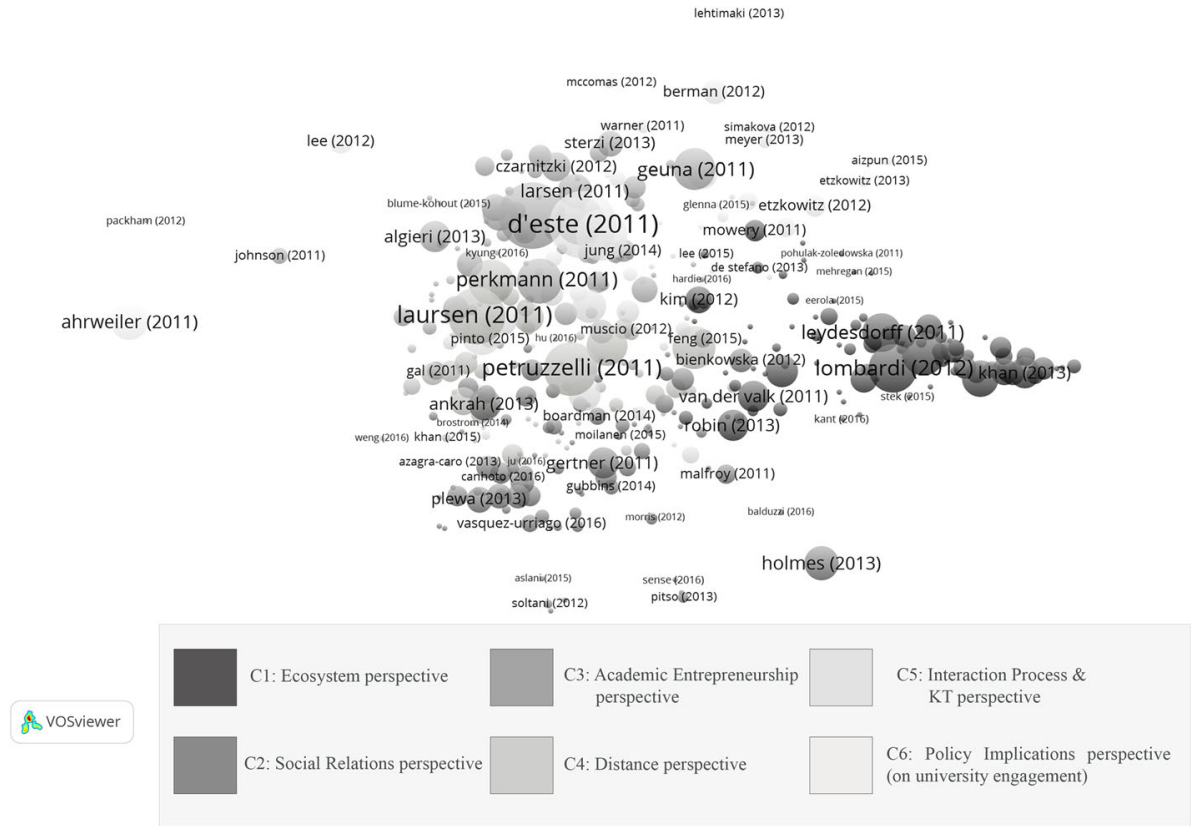

Fig. 4 A visualised bibliometric network of clustered articles included in the dataset, using bibliographic coupling technique

composed of 3 and 2 articles, respectively; due to the low applicability, these were excluded from further analysis. Thus, the final sample of analysis consists of 397 clustered articles.

Based also on the bibliographic coupling results, we retrieved the corresponding information enabling an analysis of the journals publishing the relevant literature and the keywords that are assigned to these publications. Figure 5 represents the journals publishing most research on U-I collaborations, based on the number of scientific publications per journal in the period of 2011-2016. The three leading journals are Research Policy (42 publications), followed by Journal of Technology Transfer (39 publications) and Scientometrics (32 publications). A term frequency analysis was performed revealing the most occurring keywords assigned to the publications (Fig. 6).

Applying the visualisation of similarities (VOS) approach and the bibliographic coupling technique, the existing research was divided into six thematic clusters and labelled based on the authors' independent content analysis.

\subsubsection{Cluster 1: Ecosystem perspective}

A central tenet of this cluster is the interplay between university, industry and government (i.e., Triple Helix). Largely, articles focus on explaining the impact of these three elements on joint collaborative activities on regional and national levels, including the economic and societal impact, as well as on innovation outcomes. In addition, articles belonging to this cluster also examine the dynamics of Triple Helix infrastructure (Kwon et al. 2012; Lei et al. 2012). In the context of U-I collaborations, the ecosystem perspective addresses the university policy developments stimulating entrepreneurship-based economic development 


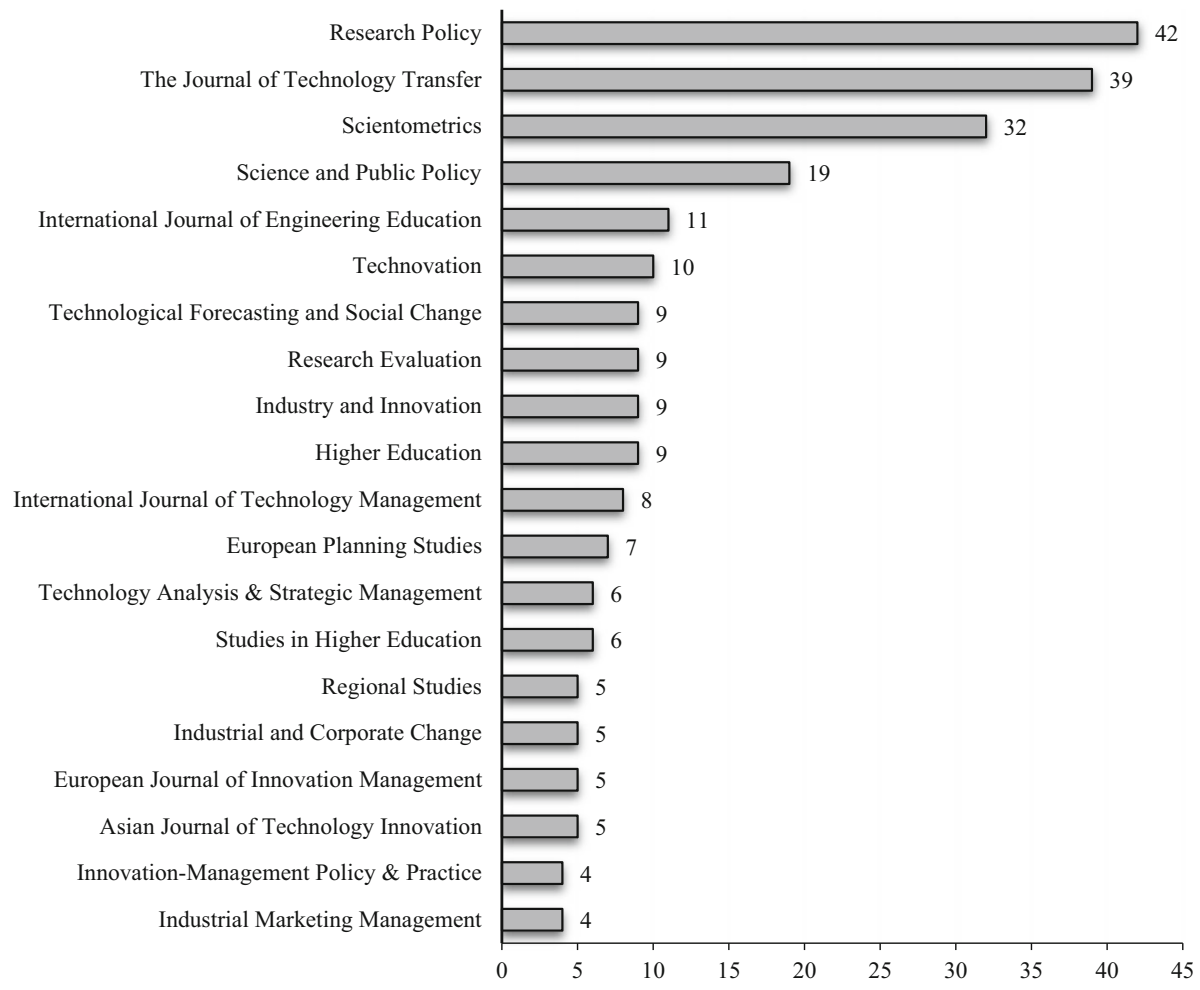

Fig. 5 Overview of the most popular journals, based on the number of scientific publications, using the bibliographic coupling technique

promoted by regional authorities (Astebro et al. 2012). In accordance with this research thread, several articles focus on understanding the exploitation possibilities of the cogenerated knowledge to bootstrap the technology of regional innovation systems (Leydesdorff and Deakin 2011). Furthermore, previous research addressed the need to develop new performance indicators to estimate the impact of U-I collaborations on the regional level, also considering the development of the e-government domain (Khan and Park 2013; Meyer et al. 2014).

\subsubsection{Cluster 2: Social relations perspective}

The largest cluster in terms of included articles focuses on the social aspect of U-I collaborations and knowledge transfer. The social relations perspective cluster corresponds to the social component of the interaction channels cluster (as part of co-citation analysis results), focusing on the effectiveness of interaction and communication among the partners. Here, articles centre around factors that facilitate and optimise sustainable relationships between actors, incentives for collaboration, and networking activities that foster reliable knowledge and technology transfer. In fact, research focuses not only on determining the relational success factors (e.g., communication, trust, understanding individuals) but also on the necessity to leverage the technical and networking competences (Comacchio et al. 2012; Plewa et al. 2013a). Correspondingly, research addresses the 


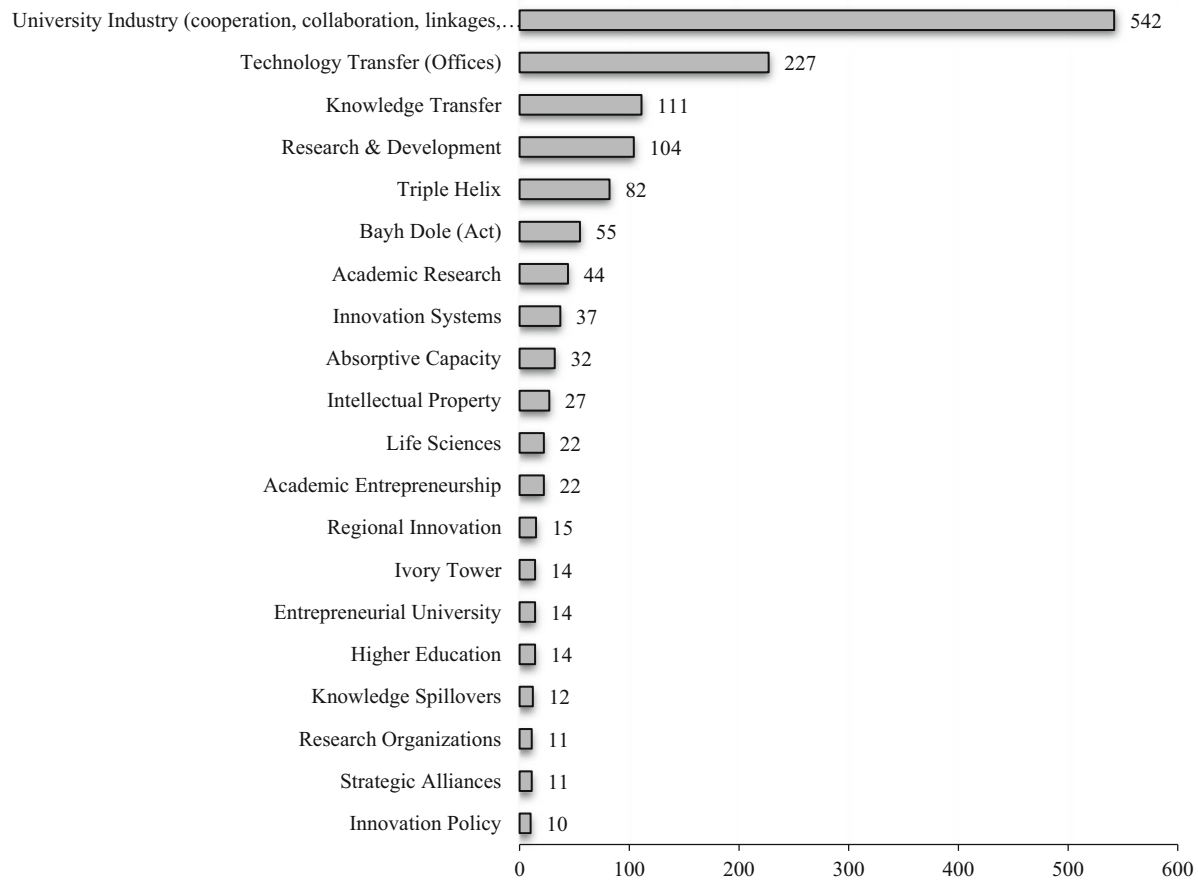

Fig. 6 Overview of the most frequent keywords assigned to the articles, using the bibliographic coupling technique

importance of developing an understanding of differences in these relational success factors across various cognitive, normative and regulative contexts (Hemmert et al. 2014). Similarly, the motives of the collaboration (e.g., more technical or more scientific) need to be considered in the process of researching into relational aspects of U-I collaborations (Soh and Subramanian 2014). Therefore, a key focus of this research direction is targeted to identify the best practices of U-I collaboration management (Morandi 2013).

\subsubsection{Cluster 3: Academic entrepreneurship perspective}

This cluster largely is composed of articles capturing the interface of knowledge and technology transfer by means of academic spin-offs and patents. Here, research focuses on characteristics of entrepreneurial universities and their motivations stimulating academics to engage in inter-organisational R\&D projects. On a broader level, the academic entrepreneurship perspective analyses the interplay of different actors embedded in the academic entrepreneurship ecosystem and the associated outcomes. Consequently, this cluster investigates different types of interaction channels, including the human capital movement, for knowledge and technology transfer and the associated outcomes at the regional level (Perkmann et al. 2013; Teixeira and Mota 2012). Additionally, understanding the antecedents and consequences of academic entrepreneurship continues to attract research interest. A prime example of research belonging to this cluster is conducted by D'Este and Perkmann (2011), examining the channels of knowledge transfer based on the research-related or commercialisation motives of scientists. Similarly, the academic 
entrepreneurship research is focused on evaluating the effects of extrinsic and intrinsic incentives for engaging in U-I collaborations taking account of the researchers' social context (Lam 2011; Tartari et al. 2014). A related stream of literature comprising this cluster addresses the characteristics of the entrepreneurial universities and factors that foster and hinder entrepreneurial activities of academic institutions (Maietta 2015).

\subsubsection{Cluster 4: Distance perspective}

This cluster focuses on understanding the structure of U-I collaborations. Articles explore the impact of spatial, social, institutional and cognitive proximities on the development and innovation performance of U-I collaborations, comparing both regional and (inter)national levels. A major part of this research direction analyses the impact of spatial proximity not only on the decisions to choose certain partners for collaborative R\&D activities but also on the new firm location choices in a proximity of related academic institutions (Abramo et al. 2011a, b). In accordance with this research stream, the impact of spatial proximity on the innovation and technology creation, as well as the regional developments, is a prime focus area (D'Este et al. 2013). However, the empirical studies of partner proximity studies report mixed results, which can be attributed to the interlinkages between different types of partner proximities, in addition to other partner technological and relation attributes (Muscio and Pozzali 2013; Petruzzelli 2011). Therefore, partner proximity is a multifaceted cluster exploring the interplay of partner proximities in conjunction with the partner absorptive capacity and exploitative/explorative capabilities (Bishop et al. 2011).

\subsubsection{Cluster 5: Interaction process and knowledge transfer perspective}

This cluster takes a dynamic view of U-I collaborations, identifying and exploring success factors and barriers of the collaboration process, both from academic and industrial perspectives. Specifically, the interaction process and knowledge transfer perspective explores different types of U-I interaction channels and their effectiveness in terms of achieving short-term or long-term goals (De Fuentes and Dutrenit 2012). Correspondingly, organisational and cultural barriers that may impede the interaction process are presented in different configurations (Gilsing et al. 2011; Kyoung-Joo 2011). The U-I interactions and associated outcomes in the form of knowledge transfer are explored from a dynamic viewpoint, resulting in options to manage and mechanisms to adjust the interactions, ranging from the early cut-off interactions to sustained interactions (Treibich et al. 2013). For example, the study of effective governance modes of U-I collaborations garnered interest from scholars by examining different levels of university involvement in relations between firms and individual academics, also considering the mediating role of university administrative structures (Bodas Freitas et al. 2013; Torres et al. 2011). The interaction process and knowledge transfer perspective also addresses the scope of different interaction channels and the extent to which universities engage in different channels by introducing the concepts of collaboration breadth and depth, respectively (Wang et al. 2015). This outlook allows to make interconnections with other perspectives, and analyse the effectiveness of different interaction channels and the type of knowledge shared mediated by the degree of partner absorptive capacity or proximity (De Fuentes and Dutrenit 2016). 


\subsubsection{Cluster 6: Policy implications perspective (on university engagement)}

Articles in this cluster analyse the management of U-I collaborations within different institutional settings and the effects of such collaborations on the regional development. This cluster is inter-linked with the ecosystem cluster (as a part of both co-citation analysis and bibliographic coupling) with a higher focus on regional policy developments as a potential catalyst or barrier for collaborative activities. Thus, this cluster is focused on understanding the logics of policy developments and normative changes on different levels (i.e., faculty, university, regional, and national) in the context of U-I collaborations, acknowledging the heterogeneity of U-I collaboration actors (Link 2015). Next to that, tracking changes in the institutional context and regional policy developments to sustain the innovation levels are central facets of this cluster (Etzkowitz 2011; Berman 2012; Robin and Schubert 2013). In the course of focusing on the university level, research suggests that the designing of policies driven not only by monetary but also by a broader range of incentives, such as reputational and intrinsic motives support the engagement in research commercialisation activities (D’Este and Perkmann 2011; Lam 2011). In turn, when it comes to the regional level, the scope and potential societal and economic impact of U-I interactions is increasingly assessed, and the corresponding policy developments need to be considered (Mathies and Slaughter 2013; Shah and Pahnke 2014). Related substreams of this cluster address the effectiveness of legal appropriation instruments regarding the scientific outputs of universities (Simeth and Raffo 2013) and the development of specific, locally adjusted strategies, considering the aggregated regional and national resources (Svensson et al. 2012).

The results of bibliographic coupling suggest a dynamic evolution of different perspectives. Two clusters with the highest number of publications (Cluster 1 and 2) received less citations on average from the academic community than the next two clusters on the list (Cluster 3 and 4) and, more interestingly, than the policy implications cluster (Cluster 6 ), which holds the highest number of average citations per article and the lowest number of publications per cluster. While this finding continues to indicate a high popularity and importance of the ecosystem perspective (Cluster 1) and the social relations perspective (Cluster 2) in the research in the past years, more notable development could be attributed to the previously noted policy implications perspective (Cluster 6), as well as to the academic entrepreneurship perspective (Cluster 3) and distance perspective (Cluster 4). This finding is intriguing in relation to the results of co-citation analysis. While the distance perspective (Cluster 4 ) and the role of partner proximity remained leading in terms of citations, it is not the most researched theme in the past 6 years, compared to other perspectives. This finding is different from the results of co-citation analysis, where the distance perspective had the highest number of publications and received citations. Certain changes are related to the academic entrepreneurship perspective (Cluster 3 ). This theme remained well-researched among the U-I academics; however, this research direction shows an increased importance in terms of received citations, based on bibliographic coupling results. In comparison, in the case of co-citation analysis, academic entrepreneurship was not the leading perspective. Additionally, the fact that the policy implications perspective (Cluster 6) has the highest number of citations on average per article indicates the relevance of this research stream. This cluster is represented by a variety of seminal works, highlighting a broad scope of the policy developments on different levels of U-I interactions. Overall, the results show a dynamic evolution of the research field and a development of interconnections among the research directions. This 
finding, in turn, emphasises the need to identify future research avenues in relation to the latest developments in the U-I literature (Table 2).

Table 2 Key statistical indicators of the clustered publications, based on the bibliographic coupling technique

\begin{tabular}{|c|c|c|c|c|c|}
\hline & $\begin{array}{l}\text { Number of } \\
\text { publications }\end{array}$ & $\begin{array}{l}\text { Total } \\
\text { citations } \\
\text { per } \\
\text { cluster }\end{array}$ & $\begin{array}{l}\text { Average } \\
\text { citations per } \\
\text { publication }\end{array}$ & $\begin{array}{l}\text { Average } \\
\text { existence of } \\
\text { publications (in } \\
\text { years) }\end{array}$ & $\begin{array}{l}\text { Three most } \\
\text { cited articles } \\
\text { (citations) }\end{array}$ \\
\hline $\begin{array}{l}\mathrm{C} 1: \text { Ecosystem } \\
\text { perspective }\end{array}$ & 96 & 662 & 6.90 & 3.21 & $\begin{array}{l}\text { Lombardi et al. } \\
\text { (2012); } 63 \\
\text { Leydesdorff and } \\
\text { Deakin } \\
\text { (2011); } 49 \\
\text { Leydesdorff and } \\
\text { Rafols (2011); } \\
38\end{array}$ \\
\hline $\begin{array}{l}\mathrm{C} 2 \text { : Social relations } \\
\text { perspective }\end{array}$ & 93 & 453 & 4.87 & 2.96 & $\begin{array}{l}\text { Holmes (2013); } \\
30 \\
\text { Ankrah et al. } \\
(2013) ; 28 \\
\text { Gertner et al. } \\
\text { (2011); } 25\end{array}$ \\
\hline $\begin{array}{l}\text { C3: Academic } \\
\text { entrepreneurship } \\
\text { perspective }\end{array}$ & 74 & 727 & 9.82 & 3.14 & $\begin{array}{l}\text { Grimaldi et al. } \\
\text { (2011); } 116 \\
\text { Van Looy et al. } \\
\text { (2011); } 60 \\
\text { Perkmann et al. } \\
\text { (2011); } 53\end{array}$ \\
\hline C4: Distance perspective & 64 & 556 & 8.69 & 2.77 & $\begin{array}{l}\text { Laursen, } \\
\text { Reichstein } \\
\text { and Salter } \\
\text { (2011); } 86 \\
\text { Petruzzelli } \\
\text { (2011); } 75 \\
\text { Bishop et al. } \\
\text { (2011); } 52\end{array}$ \\
\hline $\begin{array}{l}\text { C5: Interaction process } \\
\text { and knowledge } \\
\text { transfer perspective }\end{array}$ & 38 & 161 & 4.24 & 2.87 & $\begin{array}{l}\text { Gilsing et al. } \\
\text { (2011); } 29 \\
\text { De Fuentes and } \\
\text { Dutrenit } \\
\text { (2012); } 27 \\
\text { Bodas Freitas, } \\
\text { et al. (2013); } \\
24\end{array}$ \\
\hline $\begin{array}{l}\text { C6: Policy implications } \\
\text { perspective (on } \\
\text { university } \\
\text { engagement) }\end{array}$ & 32 & 402 & 12.56 & 4.19 & $\begin{array}{l}\text { D'Este and } \\
\text { Perkmann } \\
\text { (2011); } 119 \\
\text { Lam (2011); } 70 \\
\text { Perkmann et al. } \\
\text { (2011); } 43\end{array}$ \\
\hline
\end{tabular}




\section{Discussion and future research agenda}

This review presents the immense contribution that the analysis of U-I collaborations makes to various research streams. However, a mounting interest in this topic requires a consolidation with new theoretical and empirical insights. Specifically, the results of our bibliographic coupling and co-citation analysis of the U-I literature suggest several axes of development that could help augment the contributions of $\mathrm{U}-\mathrm{I}$ research. The presented findings and future research avenues are of critical importance to the parties involved in the U-I collaborations, including researchers and policy makers.

The U-I collaboration literature has expanded in the past two decades, recognising a tremendous potential to facilitate economic and societal development on regional and national levels by means of joint innovative developments and high-tech spin-offs. At the same time, researchers indicated that the complexity of these collaborations is not well understood (D'Este and Patel 2007; Petruzzelli 2011). The main perspectives that provide a foundation for the U-I literature are illustrated in Fig. 7. Based on the co-citation analysis, we identified four thematic clusters centred around distance and partner complementarity (Cluster 1), academic entrepreneurship (Cluster 2), ecosystem (Cluster 3) and interaction channels (Cluster 4) dimensions of U-I collaborations. While sharing a similar development pattern, these dimensions were diversified and redesigned in the past 6 years, therefore presenting a challenge to understand the scope of current research areas, and particularly the future research advancements.

We tracked the evolution of the U-I literature and examined a transformation of the current research dimensions in the field, using the bibliographic coupling technique. As indicated in Fig. 8, the ecosystem (Cluster 1) and social relations perspectives (Cluster 2) share an upward development in the period over the past 6 years, while levelling off

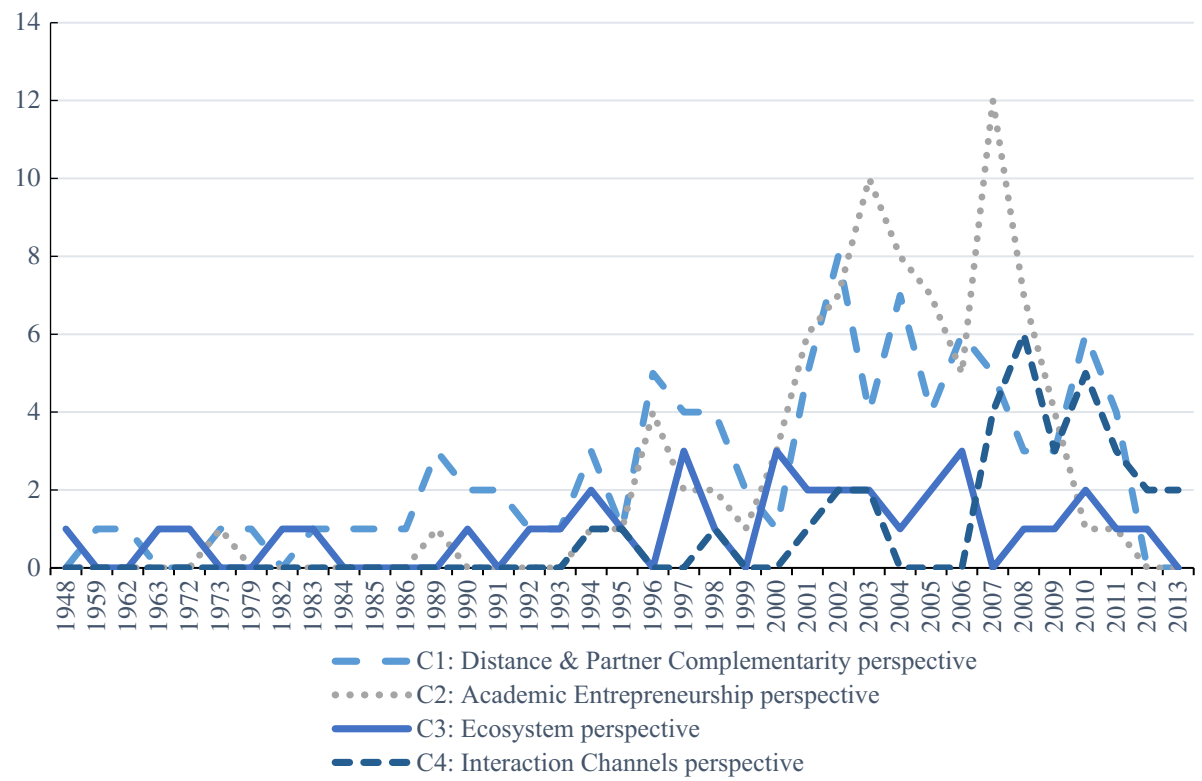

Fig. 7 Overview of the evolution of four thematic clusters per year, representing the number of articles, based on the references of the initial dataset, using co-citation analysis technique 


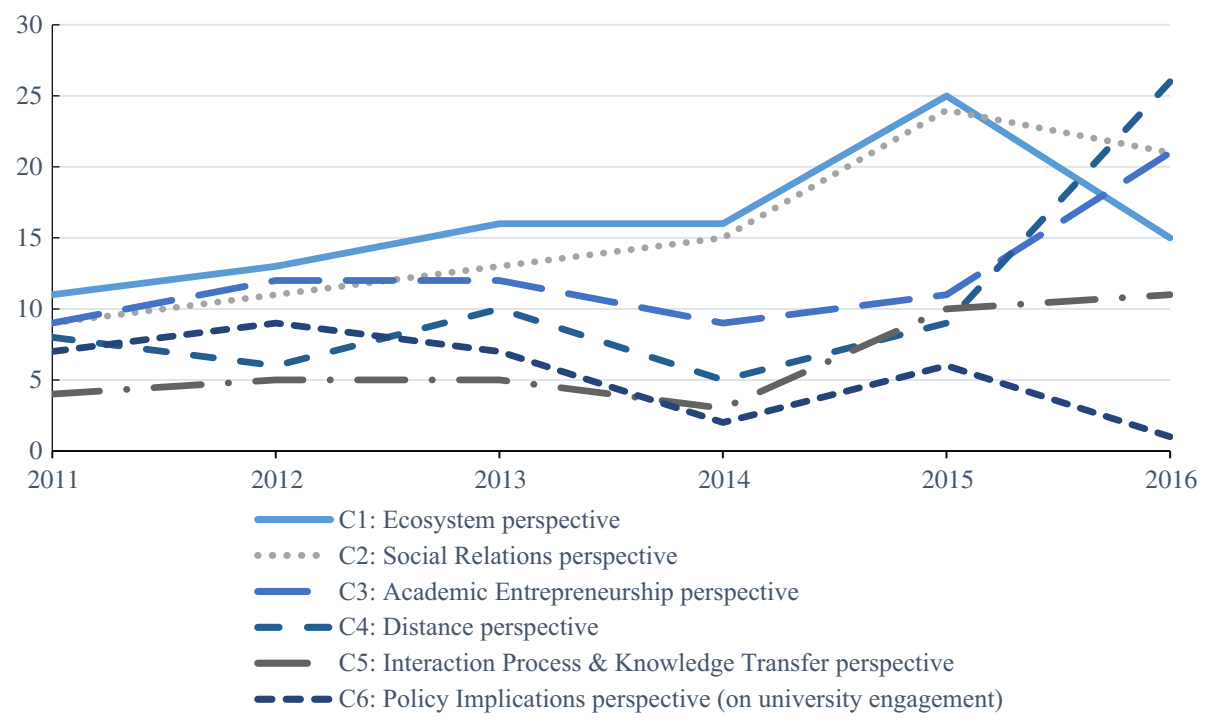

Fig. 8 Overview of the evolution of six thematic clusters per year, representing the number of articles published each year from the period of 2011 to 2016, using bibliographic coupling technique

recently and maintaining a position of crucial research areas. The Interaction process and the knowledge transfer perspective (Cluster 5) shows an increase of research articles in the last couple of years, highlighting a broad variety of factors determining the efficiency of the interaction process and relations to other perspectives. The policy implications perspective (Cluster 6) remained relatively stable without major peaks, suggesting that policy implications are not entirely explored and could be optimised. The most prominent avenues for future research are related to the academic entrepreneurship (Cluster 3) and distance perspective (Cluster 4). These research domains were studied in the past years; however, researchers identified new sub-streams that also present stimuli for future studies.

The results of the quantitative bibliometric analysis of the U-I literature indicate that the clusters share a notable portion of inter-linkages among the main elements of U-I collaborations, suggesting a multi-layered nature of the U-I research field. Specifically, the results of the co-citation analysis and bibliographic coupling indicate that it is possible to synthesise the U-I research field into three interconnected levels that form the primary future research directions, based on the identified clusters: individual level (corresponding to the social relations perspective, academic entrepreneurship perspective (i.e., young graduates and academic staff level) and interaction process and knowledge transfer among individuals); organisational level (distance perspective, academic entrepreneurship perspective (i.e., university level) and organisational interaction process and knowledge transfer); institutional level (ecosystem perspective and policy implications perspective). The three interconnected levels address a variety of stakeholders, such as researchers, universities, firms, TTCs (Technology Transfer Centres), governments, and ecosystems. However, even though the literature acknowledges the diversity of stakeholders, most of the studies pronounce the university perspective rather than the industry perspective on UI collaborations. 


\subsection{The individual in university-industry collaborations}

On the individual level, with regard to the social relations perspective, U-I scholars recognise the importance of the relationships between the individuals involved in the collaborative U-I activities. While the recent research endeavours must be applauded, there is still a long way to go on the question of what individual-level characteristics and motives should be possessed by academics and industrial partners to successfully collaborate, and particularly to manage the relationships over time to achieve strong outcomes (Filippetti and Savona 2017; Maietta 2015). Given that the characteristics and motives of academics and industrial partners differ when it comes to U-I collaborations, in addition to within-group variations (Link 2015), it is likely that the mechanisms for governing U-I relationships are highly varied in nature. In particular, future studies are recommended to investigate which types of governance mechanisms are effective depending on partners' motives and characteristics. For example, firms investing in university research projects may be interested in an alignment of goals as well as commitment between the collaboration partners (Mora-Valentin et al. 2004). A successful alliance needs goal-oriented management (Kale and Singh 2009), so that from the firm perspective it may be beneficial to apply control mechanisms. However, as researchers tend to have a high need for autonomy in setting research directions and managing their research in U-I projects (Zalewska-Kurek et al. 2016), a balance between control-based and more open or heterarchical governance may need to be negotiated to fit the expectations and needs of both partners. With regard to the partners' characteristics, for firm partners managing a portfolio of relationships, weak ties/loosely coupled relations may be the preferred mechanism to create spaces of dynamism and thereby generating profits from the engagement in a variety of U-I collaborations. Weak ties are characterised by low interaction frequency and can enable access to new, non-redundant knowledge (Granovetter 1973). However, stronger ties might want to be established on behalf of the firm partner when interacting with a specific star scientist or a group of scientists who significantly contribute to the firm's knowledge base. In turn, academics—due to their dual, complex nature of employment as researchers at universities and as self-employed within U-I collaborations-may want to build strong ties characterised by high interaction frequency, and social proximity to create spaces of stability. In addition, stronger ties between the U-I collaboration partners might be more effective for generating substantial knowledge-related benefits, while weaker ties could be more suitable in service-provision partnerships for generating financial benefits on the part of research organisations (Arza and Carattoli 2017). It would be intriguing to analyse which type of social capital comes to the fore in U-I collaborations, why, and with what effects. Moreover, the governance mechanisms may vary according to the stage of the cooperation. While there initially may be a strong focus on formal governance mechanisms to reduce uncertainty within the collaboration, some partners may put more emphasis on informal mechanisms such as trust as the U-I collaboration gradually develops-which might explain why some U-I collaborations are more or less successful than others. This is because in joint $R \& D$, neither the goals nor the contributions of the partners can be defined completely ex ante and thus hierarchical tools of control and sanction (e.g., Adler 2001; Williamson 1991) fail to coordinate innovative cooperative behavior over time (Hatak et al. 2015). Here, we encourage researchers to extend current research by engaging in cross-stage studies. Additionally, we must acknowledge that the U-I relationships are shaped by institutional environments in which the academics and the industry partners are embedded, thus affecting the (expected) outcomes from joint R\&D activities (Frasquet 
et al. 2012; Hemmert et al. 2014; Morandi 2013). Thus, it is necessary to consider the institutional context as a moderator in the relationship between governance mechanisms and outcomes of U-I collaborations. Moreover, future studies could focus on optimising the management of a portfolio of incentives and initiatives that foster U-I linkages during different evolutionary stages of partnerships (Ankrah et al. 2013; Plewa et al. 2013b). Correspondingly, there is a need to investigate which incentives not only enhance both researchers and industry partners' willingness to engage in U-I partnerships, but also foster the development of long-lasting strategic alliances. Understanding the mechanisms enabling to maintain long-term U-I relations would improve the viability of the knowledge transfer, forming the basis for further R\&D projects with reduced barriers. According to Bienkowska and Klofsten (2012), fostering the development of relationships among the partners could be achieved by promoting commercialisation of research results (CRR) skills and providing new opportunities for $\mathrm{PhD}$ candidates through courses, graduate schools and interactive research designs. At the same time the question remains of how U-I collaboration can be made attractive for partners from the industry by incentives other than funding schemes.

Research focusing on Academic Entrepreneurship explores the characteristics and motives of the academic entrepreneur, the entrepreneurial university, and the context in which the actors of academic entrepreneurship are embedded, and their effects on spin-off success. The central element connecting these layers of academic entrepreneurship is the entrepreneur (Perkmann et al. 2013; Tartari and Breschi 2012). The increasing resources devoted to understanding the behavioural outcomes associated with entrepreneurs' identity in general calls for U-I research that identifies different types of identities among academic entrepreneurs in particular. This is an interesting avenue as academics need to integrate their academic self-concept and their entrepreneurial self-concept, resulting in either hybrid identities or pure identities, which, in turn, offer explanations of the commercial behaviour of academics (Abreu and Grinevich 2017). In this regard, it is important to explore the intrinsic and extrinsic motivations driving entrepreneurial behaviour of academics, such as time spent and duration of engagement capturing behavioural intensity and persistence (Lam 2011). To analyse behavioural intensity and persistence, one might use experience sampling methodology (Uy et al. 2010). As shown by research on the motivations of academics to start a spin-off, their motives differ (Fini et al. 2009; Hayter et al. 2016; Rizzo 2015) so that their identities can also be expected to be heterogeneous (Clarysse et al. 2011). Another interesting research avenue that we propose would be to examine the university spin-offs' (USOs) failures and the associated failure factors on the level of the individual actors. While academic entrepreneurship has a long tradition of examining success factors, it might actually be the focus on failure factors that has the potential to provide counterintuitive and therefore relevant new insights. Furthermore, a relatively new stream of literature points to the impact of students, recent graduates and young academics on regional innovative development. Identifying the factors and conditions that stimulate these actors to increasingly engage in the commercialisation activities of their research and understanding the scope of this ecosystem would be of significant value (Laursen et al. 2011; Astebro et al. 2013; Wright et al. 2017). Such studies might provide answers to questions that have been only partially addressed: What are the characteristics of the graduates that start companies (e.g., Larsson et al. 2017)? Under what conditions do they start their companies? Furthermore, what types of entrepreneurship education (e.g., regular courses, bootcamps, start-up weekends, teaching methods directed towards creating an entrepreneurial mind-set, attitude and orientation) actually increase students' and recent graduates' entrepreneurial preferences and their subsequent translation 
into start-up actions? For example, is the lean start-up methodology more effective the traditional business methodology? Experimental studies might enable researchers to disentangle the various influences of entrepreneurship education at the different sub-stages of the entrepreneurial process, such as the development of intentions, start-up actions and young venture development. In addition, exploring the effects of start-up activity by recent university graduates, $\mathrm{PhDs}$ and post-docs on the human capital movement in the region and the $\mathrm{R} \& \mathrm{D}$ performance of the region, respectively, are crucial research dimensions (Laursen et al. 2011). Recently, an excellent outlook on future academic entrepreneurship research has been drawn by Siegel and Wright (2015), to which we refer the interested reader. The authors discuss in more detail some of the abovementioned avenues, among others.

\subsection{The organisation in university-industry collaborations}

On the organisational level, with regard to the academic entrepreneurship perspective, the U-I literature can be consolidated into the analysis of the characteristics of universities engaging in joint research activities, characteristics of firms seeking to collaborate with academic partners and the characteristics of the collaboration process itself. There are studies indicating why firms and universities engage in joint projects, but research on the determinants of private and public gains of university involvement in research partnerships with industrial partners is still at a nascent stage (Link 2015). In this regard, much research attention needs to be devoted to the heterogeneity of U-I partners. It is likely that the antecedents and consequences of academic entrepreneurship differ when taking account of, for example, the firm size, age, and competitive strategy of the industrial partner, and the size, age/ranking, type of university. On a related note, research on the impact of a specific department's excellence regardless of the university ranking on decisions to engage in partnerships on regional, national or international levels could yield interesting findings (Laursen et al. 2011). Furthermore, while there have been calls for research on firms' strategies when searching for and selecting academics as collaboration partners (see e.g., Perkmann and Walsh (2007), the industry's criteria driving the choice of a specific academic partner for a collaborative research project remains an underexplored topic (Link 2015). Special attention needs to be devoted to the strategic and cultural fit between university and industry partners for understanding the successful organisation and management of their collaborative projects. Finally, new success factors of university entrepreneurship projects should be examined in the future studies, which could be achieved by the systematic evaluation of failed projects and collaborations, and particularly the factors of failure at different stages of project life-cycle (Bozeman et al. 2013; Guzzini and Iacobucci 2017).

While the distance perspective offers an increasing understanding of the outcomes of partner spatial, cognitive, organisational, social and institutional proximities, the multidimensionality and broad scope of this perspective suggest further research opportunities (Crescenzi et al. 2017; D'Este et al. 2013). The academic understanding of U-I partnership's evolvement and outcomes may benefit from exploring the interplay of different types of proximities and associated dynamics (Muscio and Pozzali 2013; Presutti et al. 2017). Here, future studies could further examine whether and how a specific type of proximity can foster the development of other proximity types-for example, spatial proximity may lead to social proximity - as well as whether one type of proximity may replace another depending on the context in which the U-I collaboration is embedded (Crescenzi et al. 2017). However, as the capturing of direct and particularly indirect effects of partner proximity remains challenging, researchers are encouraged to develop 
alternative outcome indicators to reliably estimate the effects of partner proximity in the context of joint R\&D activities (D’Este et al. 2013; Fukugawa 2013). Moreover, our review points to the benefits of focusing the distance perspective research on partner centrality and closeness. For instance, what is the role of central partners within the network regarding the joint project success (von Raesfeld et al. 2012)? Specifically, future research could examine how central partner presence in collaborative projects affects the capability to generate innovative outcomes, potentially through the optimisation of accessible knowledge and technology inputs (Qi Dong et al. 2017). In this regard, the role of other factors complementing or mediating the impact of partner proximity is an interesting area for future studies. For example, the availability of research resources, the partner technological complementarity and the level of absorptive capacity in conjunction with partner proximity remain important topics for future studies (Bishop et al. 2011; Laursen et al. 2011; Petruzzelli 2011). Another unexplored aspect of the proximity stream within the U-I literature is the extent of industry involvement in the creation of university spin-off (USOs). Academic entrepreneurship has mainly been supported by the university and government (Meyer 2003; Fini et al. 2011; Grimaldi et al. 2011); however, it can be also supported by the (local) industry. Simultaneously, firms may even decide for locations that are geographically close to research organisations to benefit from knowledge spillovers (Audretsch et al. 2005). Anecdotal evidence suggests that industry partners geographically close to the university provide academic commercial ventures with access to facilities and knowledge from their business development units (private business clusters or incubators) rather than with substantial capital funds. While there is research on the shaping of industries' support in the early stages of spin-off development (e.g., Zhang 2009), the mutual resource flows between USOs and their industry partners over time and in conjunction with partner proximity have received little conceptual and empirical attention.

\subsection{The institutions in university-industry collaborations}

On the institutional level, the literature points to the economic and societal impact generated by U-I collaborations on regional and national levels as well as to an increasing importance of policy developments that would maximise the effectiveness of U-I interactions (Filippetti and Savona 2017). In the last decade, different configurations of Triple Helix interactions that frequently form a complex system of inter-dependent relations have been developed (Lei et al. 2012). Based on our review, future research embedded in the ecosystem perspective would benefit from examining what types of Triple Helix network configurations are most effective, considering institutional differences across countries and regions (Etzkowitz 2011; Guan and Zhao 2013; van der Valk et al. 2011). In this regard, prior research calls for the development of performance indicators that would reliably predict what configurations are necessary to optimise collaborative project success between university-industry-government (Feller 2017; Leydesdorff and Rafols 2011). Pursuing this research avenue will become increasingly relevant due to the development of an e-government domain (Khan and Park 2011). In addition, given the recent increase in opportunities (e.g., university/public funding support for U-I projects) and the threats (e.g., weak IPR protection) in the context of (international) U-I collaboration, future research is recommended to extend the framework of university-industry-government relations towards Quadruple Helix, thus expanding the facets of U-I collaborations that are examined (Leydesdorff 2012; Marcovich and Shinn 2011). Moreover, a relevant exploration of network configurations needs to account for differences between industry sectors and technology fields (Guan and Zhao 2013; Kwon et al. 2012) as well as between 
scientific fields. It can be expected that all scientific fields have an impact on economy and society; however, social sciences have largely been left out in U-I collaborations research despite their contributions to the competitiveness and innovativeness of the economy by providing e.g., new research tools and interventions in conjunction with consultancy, knowledge on the effectiveness of management approaches, highly skilled and entrepreneurially educated graduates among other outcomes. More research could be done on the question of how and with what effects knowledge is transferred from social sciences to the society at large.

With regard to the policy implications perspective, research argues that universityindustry-government interactions can be shaped by civic involvement and their characteristics, in addition to cultural and social capital endowments (Lombardi et al. 2012). Thus, it is worthwhile to investigate how changes in the local institutional environment foster the engagement of academics in collaborative research projects and university spinoff creation (Fini et al. 2011). Conversely, it would be interesting to examine how U-I collaborations affect policy development, requiring approaches that are multi-disciplinary and historical in nature. In relation to the incentives that could stimulate engagement in UI collaborative projects on the part of academics, research should consider that collaboration with industry does not necessarily foster success in academia. As indicated by Lee and Miozzo (2015), the engagement in industry-involved projects by physicists and engineering $\mathrm{Ph}$.D. researchers is negatively related to their career in academia. It is therefore not only up to the university but the entire science system including policy makers to come up with an incentive scheme specifying how and when academics can be promoted if they engage in the third mission of the university. This issue need to be further explored by research, outlining the characteristics and conditions of best practices.

The process perspective (interaction process and knowledge transfer cluster) of U-I collaborations is not a core research stream; however, there is a strong need for future examinations, especially if we want to understand the complex processes of interaction between academia and industry, resulting in a long-term exchange of knowledge and technological resources at all levels of U-I collaboration (Gilsing et al. 2011). In line with McMullen and Dimov (2013), there are a number of conceptual questions that require answers if a process perspective to U-I collaborations shall gain momentum: What is the U-I collaboration journey, when has this journey started, when has this journey concluded, does it require particular interactions to progress; and what remains constant and what changes throughout the process of interaction between U-I partners? Longitudinal studies could help to answer those questions and capture the depth and breadth of interaction cycles, beginning with an initiating action and both the academics' and industry partners' reactions. Finally, our review points to the benefits of extending the level of analysis of future U-I interaction process studies beyond the individual level to ask-among other questions-whether industry partners in the same industry react in similar ways, how interaction is developed at higher levels, that is between the firm, the university and the government, and how such interactions shape the dynamics of academia, the industry and the institutional environment.

A summary of the emerging patterns outlining the future research agenda is provided in Table 3.

\subsection{Research limitations}

Inevitably, this study also has certain limitations paving the way for several extensions of the bibliometric analysis of U-I collaboration research and additional analyses. First, this 
Table 3 Overview of emerging research agenda and sample research questions

\begin{tabular}{lll}
\hline $\begin{array}{l}\text { Level of } \\
\text { analysis }\end{array}$ & Associated clusters & Exemplary research questions \\
\hline
\end{tabular}

Individual Social relations perspective
level

Academic entrepreneurship perspective (i.e., recent graduates and academic staff level)

Individual interaction process and $\mathrm{KT}$ (i.e., communication mechanisms)

Organisational
level $\begin{gathered}\text { perspective (i.e., university level) } \\ \text { perspepreneurship }\end{gathered}$

Distance and partner complementarity perspective
What are the mechanisms to effectively integrate different motives of U-I collaboration partners during different stages of U-I collaborations?

How do cognitive, normative and regulatory differences affect the coordination and productivity of relationships among U-I collaborations partners?

Through which strategic incentives can universities motivate both researchers and firms to enter into U-I partnerships and turn them into lasting strategic alliances?

How can we differentiate between different types of entrepreneurs in terms of academic entrepreneurial identity, and how do different types of identities affect the success of U-I collaborations?

How do academic entrepreneurs contribute to the failure of USOs?

What is the impact of students and recent graduates on the regional economic development by means of academic/student spin-offs?

Which U-I interaction channels stimulate the generation of knowledge-related and monetary benefits in the short term and long term on the individual level?

Which organisational characteristics of the university and the industry partner explain success at different stages of the spin-off lifecycle?

How does the quality of a university department affect the U-I collaboration success, notwithstanding the overall quality of the university?

Which factors influence the industrial partners' selection of academic partners for collaborative research partnerships?

Which characteristics of universities and industrial partners, and their interorganizational collaboration contribute to the failure of U-I partnerships?

How does the interplay of different partner proximities influence the evolution and performance outcomes of U-I collaborations?

Which alternative success indicators can be used to capture the dynamics of partner proximities?

What is the impact of partner network position and technological complementarity on the performance of U-I collaborations? 
Table 3 continued

\begin{tabular}{|c|c|c|}
\hline $\begin{array}{l}\text { Level of } \\
\text { analysis }\end{array}$ & Associated clusters & Exemplary research questions \\
\hline & $\begin{array}{l}\text { Organisational interaction process and } \\
\text { KT }\end{array}$ & $\begin{array}{l}\text { Which U-I interaction channels stimulate the } \\
\text { generation of knowledge-related and } \\
\text { monetary benefits in the short term and long } \\
\text { term on the organisational level? } \\
\text { What are the differences between formal and } \\
\text { informal interaction channels in the U-I } \\
\text { collaboration process? }\end{array}$ \\
\hline \multirow[t]{2}{*}{$\begin{array}{l}\text { Institutional } \\
\text { level }\end{array}$} & Ecosystem perspective & $\begin{array}{l}\text { What configurations of university-industry- } \\
\text { government interactions stimulate the } \\
\text { regional economic development, considering } \\
\text { institutional differences across countries and } \\
\text { regions? } \\
\text { Which metrics can be used to estimate direct } \\
\text { and indirect effects of U-I collaborations on } \\
\text { regional economic and societal development? } \\
\text { What is the impact of social sciences on the } \\
\text { innovativeness and competitiveness of the } \\
\text { economy? How can the transfer of knowledge } \\
\text { from social sciences to industry be enhanced? }\end{array}$ \\
\hline & Policy implications perspective & $\begin{array}{l}\text { How can regional policy developments foster or } \\
\text { hinder the development of university- } \\
\text { industry collaborations and their outcomes? } \\
\text { How do university-industry collaborations } \\
\text { affect policy developments? } \\
\text { What are the implications of engaging in U-I } \\
\text { collaborations for careers of researchers? }\end{array}$ \\
\hline
\end{tabular}

study investigates a specific dataset on U-I collaborations. However, the results show that each of the identified perspectives in this paper could be investigated independently. Thus, it is necessary to extend the scope of the U-I literature among the identified research perspectives. Additionally, using other keywords for data collection may lead to broader research directions. Second, the main goal of this study was to grasp the latest research advancements. Future studies could explore the interplay of our findings in comparison to the entire field while imposing no time limitations. Third, our dataset is focused on the most recent publications; therefore, the weight of the publications used for creating the clusters of literature will change according to the citation patterns of this research field. Finally, imposing a threshold on the number of citations for co-citation hinders an analysis of the entire literature, which also ignores potentially relevant but primarily recent publications. An investigation of different datasets compiled on the basis of other keyword combinations and extended period of publication time could enable us to identify additional elements of U-I collaborations and academic entrepreneurship and establish new interlinkages across the U-I ecosystem.

\subsection{Conclusion}

This study examined the nature of the U-I collaborations research using both quantitative and qualitative methods of analyses, concluding that the research field is complex and 
multi-faceted. Based on co-citation analysis, we analysed the evolution of the research field and identified fundamental research themes. By using the method of bibliographic coupling, we were able to investigate current and emerging topics of interest in the study of UI collaborations. Based on our comprehensive content analysis, we were able to identify linkages between the different perspectives adopted in U-I collaborations research, thus contributing to integration of diverse research streams and a clarification of the scope of the U-I collaborations literature. The findings of our bibliometric study suggest that the U-I collaborations research can be seen as a multi-layered ecosystem consisting of interconnected perspectives on individual, organisational and institutional levels. Our study concludes by offering a nuanced research agenda with valuable implications for academics and policy makers.

Acknowledgements The authors are grateful to Bart van Looy for a constructive feedback and helpful comments on the earlier versions of this paper, especially at the early stage of this work, as well as participants of the 2017 R\&D Management conference in Leuven for useful suggestions. The authors also acknowledge the support of the University of Twente (BMS) Tech4People initiative.

Open Access This article is distributed under the terms of the Creative Commons Attribution 4.0 International License (http://creativecommons.org/licenses/by/4.0/), which permits unrestricted use, distribution, and reproduction in any medium, provided you give appropriate credit to the original author(s) and the source, provide a link to the Creative Commons license, and indicate if changes were made.

\section{References}

Abramo, G., D'Angelo, C. A., \& Di Costa, F. (2011a). University-industry research collaboration: A model to assess university capability. Higher Education, 62(2), 163-181.

Abramo, G., D’Angelo, C. A., Di Costa, F., \& Solazzi, M. (2011b). The role of information asymmetry in the market for university-industry research collaboration. The Journal of Technology Transfer, 36(1), $84-100$.

Abreu, M., \& Grinevich, V. (2017). Gender patterns in academic entrepreneurship. The Journal of Technology Transfer, 42(4), 763-794.

Adler, P. S. (2001). Market, hierarchy, and trust: The knowledge economy and the future of capitalism. Organization Science, 12(2), 215-234.

Ankrah, S. N., Burgess, T. F., Grimshaw, P., \& Shaw, N. E. (2013). Asking both university and industry actors about their engagement in knowledge transfer: What single-group studies of motives omit. Technovation, 33(2-3), 50-65.

Anselin, L., Varga, A., \& Acs, Z. (1997). Local geographic spillovers between university research and high technology innovations. Journal of Urban Economics, 42(3), 422-448.

Arza, V. (2010). Channels, benefits and risks of public-private interactions for knowledge transfer: Conceptual framework inspired by Latin America. Science and Public Policy, 37(7), 473-484.

Arza, V., \& Carattoli, M. (2017). Personal ties in university-industry linkages: A case-study from Argentina. The Journal of Technology Transfer, 42(4), 814-840.

Astebro, T., Bazzazian, N., \& Braguinsky, S. (2012). Startups by recent university graduates and their faculty: Implications for university entrepreneurship policy. Research Policy, 41(4), 663-677.

Astebro, T., Braunerhjelm, P., \& Brostrom, A. (2013). Does academic entrepreneurship pay? Industrial and Corporate Change, 22(1), 281-311.

Audretsch, D. B., Lehmann, E. E., \& Warning, S. (2005). University spillovers and new firm location. Research Policy, 34, 1113-1122.

Bekkers, R., \& Bodas Freitas, I. M. (2008). Analysing knowledge transfer channels between universities and industry: To what degree do sectors also matter? Research Policy, 37(10), 1837-1853.

Bercovitz, J., \& Feldman, M. (2008). Academic entrepreneurs: Organizational change at the individual level. Organization Science, 19(1), 69-89.

Berman, E. P. (2012). Explaining the move toward the market in US academic science: How institutional logics can change without institutional entrepreneurs. Theory and Society, 41(3), 261-299. 
Bienkowska, D., \& Klofsten, M. (2012). Creating entrepreneurial networks: Academic entrepreneurship, mobility and collaboration during Ph.D. education. Higher Education, 64(2), 207-222.

Bishop, K., D’Este, P., \& Neely, A. (2011). Gaining from interactions with universities: Multiple methods for nurturing absorptive capacity. Research Policy, 40(1), 30-40.

Bodas Freitas, I. M., Geuna, A., \& Rossi, F. (2013). Finding the right partners: Institutional and personal modes of governance of university-industry interactions. Research Policy, 42(1), 50-62.

Boyack, K. W., \& Klavans, R. (2010). Co-citation analysis, bibliographic coupling, and direct citation: Which citation approach represents the research front most accurately? Journal of the American Society for Information Science and Technology, 61(12), 2389-2404.

Bozeman, B. (2000). Technology transfer and public policy: A review of research and theory. Research Policy, 29(4-5), 627-655.

Bozeman, B., Fay, D., \& Slade, C. P. (2013). Research collaboration in universities and academic entrepreneurship: The-state-of-the-art. The Journal of Technology Transfer, 38(1), 1-67.

Bramwell, A., \& Wolfe, D. A. (2008). Universities and regional economic development: The entrepreneurial University of Waterloo. Research Policy, 37(8), 1175-1187.

Carayannis, E. G., \& Campbell, D. F. J. (2012). Mode 3 knowledge production in quadruple helix innovation systems (pp. 1-63). New York, NY: Springer.

Clarysse, B., Tartari, V., \& Salter, A. (2011). The impact of entrepreneurial capacity, experience and organizational support on academic entrepreneurship. Research Policy, 40(8), 1084-1093.

Cohen, W. M., \& Levinthal, D. A. (1989). Innovation and learning: The two faces of R\&D. The Economic Journal, 99(397), 569.

Cohen, W. M., \& Levinthal, D. A. (1990). Absorptive capacity: A new perspective on learning and innovation. Administrative Science Quarterly, 35(1), 128.

Cohen, W. M., Nelson, R. R., \& Walsh, J. P. (2002). Links and impacts: The influence of public research on industrial R\&D. Management Science, 48(1), 1-23.

Comacchio, A., Bonesso, S., \& Pizzi, C. (2012). Boundary spanning between industry and university: The role of Technology Transfer Centres. The Journal of Technology Transfer, 37(6), 943-966.

Crescenzi, R., Filippetti, A., \& Iammarino, S. (2017). Academic inventors: Collaboration and proximity with industry. The Journal of Technology Transfer, 42(4), 730-762.

D'Este, P., Guy, F., \& Iammarino, S. (2013). Shaping the formation of university-industry research collaborations: What type of proximity does really matter? Journal of Economic Geography, 13(4), 537-558.

D'Este, P., \& Patel, P. (2007). University-industry linkages in the UK: What are the factors underlying the variety of interactions with industry? Research Policy, 36(9), 1295-1313.

D'Este, P., \& Perkmann, M. (2011). Why do academics engage with industry? The entrepreneurial university and individual motivations. The Journal of Technology Transfer, 36(3), 316-339.

Davey, T., Rossano, S., \& van der Sijde, P. (2016). Does context matter in academic entrepreneurship? The role of barriers and drivers in the regional and national context. The Journal of Technology Transfer, 41(6), 1457-1482.

De Fuentes, C., \& Dutrenit, G. (2012). Best channels of academia-industry interaction for long-term benefit. Research Policy, 41(9), 1666-1682.

De Fuentes, C., \& Dutrenit, G. (2016). Geographic proximity and university-industry interaction: The case of Mexico. The Journal of Technology Transfer, 41(2), 329-348.

Debackere, K., \& Veugelers, R. (2005). The role of academic technology transfer organizations in improving industry science links. Research Policy, 34(3), 321-342.

Delgado García, J. B., De Quevedo Puente, E., \& Blanco Mazagatos, V. (2015). How affect relates to entrepreneurship: A systematic review of the literature and research agenda. International Journal of Management Reviews, 17(2), 191-211.

Di Gregorio, D., \& Shane, S. (2003). Why do some universities generate more start-ups than others? Research Policy, 32(2), 209-227.

Diez-Vial, I., \& Montoro-Sanchez, A. (2017). Research evolution in science parks and incubators: Foundations and new trends. Scientometrics, 110(3), 1243-1272.

Dutrénit, G., De Fuentes, C., \& Torres, A. (2010). Channels of interaction between public research organisations and industry and their benefits: Evidence from Mexico. Science and Public Policy, 37(7), $513-526$.

Eisenhardt, K. (1989). Building theories from case study research. The Academy of Management Review, 14(4), 532-550.

Etzkowitz, H. (1984). Entrepreneurial scientists and entrepreneurial universities in American Academic Science. Minerva, 21(2-3), 198-233. 
Etzkowitz, H. (2003a). Research groups as 'quasi-firms': The invention of the entrepreneurial university. Research Policy, 32(1), 109-121.

Etzkowitz, H. (2003b). Innovation in innovation: The Triple Helix of university-industry-government relations. Social Science Information, 42(3), 293-337.

Etzkowitz, H. (2011). Normative change in science and the birth of the Triple Helix. Social Science Information Sur Les Sciences Sociales, 50(3-4, SI), 549-568.

Etzkowitz, H., \& Klofsten, M. (2005). The innovating region: Toward a theory of knowledge-based regional development. R\&D Management, 35(3), 243-255.

Etzkowitz, H., \& Leydesdorff, L. (2000). The dynamics of innovation: From national systems and "Mode 2" to a Triple Helix of university-industry-government relations. Research Policy, 29(2), 109-123.

Feller, I. (2017). Assessing the societal impact of publicly funded research. The Journal of Technology Transfer. https://doi.org/10.1007/s10961-017-9602-z.

Filippetti, A., \& Savona, M. (2017). University-industry linkages and academic engagements: Individual behaviours and firms' barriers. Introduction to the special section. The Journal of Technology Transfer, 42(4), 719-729.

Fini, R., Grimaldi, R., Santoni, S., \& Sobrero, M. (2011). Complements or substitutes? The role of universities and local context in supporting the creation of academic spin-offs. Research Policy, 40(8, SI), 1113-1127.

Fini, R., Grimaldi, R., \& Sobrero, M. (2009). Factors fostering academics to start up new ventures: An assessment of Italian founders' incentives. The Journal of Technology Transfer, 34(4), 380-402.

Fleming, L., \& Sorenson, O. (2004). Science as a map in technological search. Strategic Management Journal, 25(89), 909-928.

Frasquet, M., Calderon, H., \& Cervera, A. (2012). University-industry collaboration from a relationship marketing perspective: An empirical analysis in a Spanish University. Higher Education, 64(1), 85-98.

Fukugawa, N. (2013). University spillovers into small technology-based firms: Channel, mechanism, and geography. The Journal of Technology Transfer, 38(4), 415-431.

Gerbin, A., \& Drnovsek, M. (2016). Determinants and public policy implications of academic-industry knowledge transfer in life sciences: A review and a conceptual framework. The Journal of Technology Transfer, 41(5), 979-1076.

Gertner, D., Roberts, J., \& Charles, D. (2011). University-industry collaboration: A CoPs approach to KTPs. Journal of Knowledge Management, 15(4), 625-647.

Geuna, A., \& Muscio, A. (2009). The governance of university knowledge transfer: A critical review of the literature. Minerva, 47(1), 93-114.

Gilsing, V., Bekkers, R., Freitas, I. M. B., \& van der Steen, M. (2011). Differences in technology transfer between science-based and development-based industries: Transfer mechanisms and barriers. Technovation, 31(12), 638-647.

Granovetter, M. S. (1973). The strength of weak ties. American Journal of Sociology, 78(6), 1360-1380.

Granovetter, M. (1985). Economic action and social structure: The problem of embeddedness. American Journal of Sociology, 91(3), 481-510.

Grimaldi, R., Kenney, M., Siegel, D. S., \& Wright, M. (2011). 30 years after Bayh-Dole: Reassessing academic entrepreneurship. Research Policy, 40(8), 1045-1057.

Guan, J., \& Zhao, Q. (2013). The impact of university-industry collaboration networks on innovation in nanobiopharmaceuticals. Technological Forecasting and Social Change, 80(7), 1271-1286.

Guzzini, E., \& Iacobucci, D. (2017). Project failures and innovation performance in university-firm collaborations. The Journal of Technology Transfer, 42(4), 865-883.

Hatak, I., Fink, M., \& Frank, H. (2015). Business freedom, corruption and the performance of trusting cooperation partners: Empirical findings from six European countries. Review of Managerial Science, 9(3), 523-547.

Hayter, C. S., Lubynsky, R., \& Maroulis, S. (2016). Who is the academic entrepreneur? The role of graduate students in the development of university spinoffs. The Journal of Technology Transfer, 42(6), 1237-1254.

Hemmert, M., Bstieler, L., \& Okamuro, H. (2014). Bridging the cultural divide: Trust formation in university-industry research collaborations in the US, Japan, and South Korea. Technovation, 34(10), 605-616.

Henderson, R., Jaffe, A. B., \& Trajtenberg, M. (1998). Universities as a source of commercial technology: a detailed analysis of university patenting, 1965-1988. The Review of Economics and Statistics, 80(1), $119-127$.

Holmes, L. (2013). Competing perspectives on graduate employability: Possession, position or process? Studies in Higher Education, 38(4), 538-554. 
Jaffe, A. B. (1989). Real effects of academic research. The american economic review. Nashville: American Economic Association.

Jaffe, A. B., Trajtenberg, M., \& Henderson, R. (1993). Geographic localization of knowledge spillovers as evidenced by patent citations. The Quarterly Journal of Economics, 108(3), 577-598.

Kale, P., \& Singh, H. (2009). Managing strategic alliances: What do we know now, and where do we go from here? Academy of Management Perspectives, 23, 45-62.

Kessler, M. M. (1963). Bibliographic coupling between scientific papers. American Documentation, 14(1), $10-25$.

Khan, G. F., \& Park, H. W. (2011). Measuring the Triple Helix on the web: Longitudinal trends in the university-industry-government relationship in Korea. Journal of the American Society for Information Science and Technology, 62(12), 2443-2455.

Khan, G. F., \& Park, H. W. (2013). The e-government research domain: A Triple Helix network analysis of collaboration at the regional, country, and institutional levels. Government Information Quarterly, 30(2), 182-193.

Klevorick, A. K., Levin, R. C., Nelson, R. R., \& Winter, S. G. (1995). On the sources and significance of interindustry differences in technological opportunities. Research Policy, 24(2), 185-205.

Kovács, A., Van Looy, B., \& Cassiman, B. (2015). Exploring the scope of open innovation: A bibliometric review of a decade of research. Scientometrics, 104(3), 951-983.

Kwon, K.-S., Park, H. W., So, M., \& Leydesdorff, L. (2012). Has globalization strengthened South Korea's national research system? National and international dynamics of the Triple Helix of scientific coauthorship relationships in South Korea. Scientometrics, 90(1), 163-176.

Kyoung-Joo, L. (2011). From interpersonal networks to inter-organizational alliances for university-industry collaborations in Japan: The case of the Tokyo Institute of Technology. $R \& D$ Management, 41(2, SI), 190-201.

Lam, A. (2011). What motivates academic scientists to engage in research commercialization: 'Gold', 'ribbon' or 'puzzle'? Research Policy, 40(10), 1354-1368.

Larsson, J. P., Wennberg, K., Wiklund, J., \& Wright, M. (2017). Location choices of graduate entrepreneurs. Research Policy, 46(8), 1490-1504.

Laursen, K., Reichstein, T., \& Salter, A. (2011). Exploring the effect of geographical proximity and university quality on university-industry collaboration in the United Kingdom. Regional Studies, 45(4), 507-523.

Lee, H., \& Miozzo, M. (2015). How does working on university-industry collaborative projects affect science and engineering doctorates' careers? Evidence from a UK research-based university. Journal of Technology Transfer, 40(2), 293-317.

Lehmann, E. E., \& Menter, M. (2016). University-industry collaboration and regional wealth. The Journal of Technology Transfer, 41(6), 1284-1307.

Lei, X.-P., Zhao, Z.-Y., Zhang, X., Chen, D.-Z., Huang, M.-H., \& Zhao, Y.-H. (2012). The inventive activities and collaboration pattern of university-industry-government in China based on patent analysis. Scientometrics, 90(1), 231-251.

Lengyel, B., \& Leydesdorff, L. (2011). Regional innovation systems in Hungary: The failing synergy at the national level. Regional Studies, 45(5), 677-693.

Leydesdorff, L. (2012). The Triple Helix, quadruple helix, ..., and an N-tuple of helices: Explanatory models for analyzing the knowledge-based economy? Journal of the Knowledge Economy, 3(1), 25-35.

Leydesdorff, L., \& Deakin, M. (2011). The triple-helix model of smart cities: A neo-evolutionary perspective. Journal of Urban Technology, 18(2, SI), 53-63.

Leydesdorff, L., \& Fritsch, M. (2006). Measuring the knowledge base of regional innovation systems in Germany in terms of a Triple Helix dynamics. Research Policy, 35(10), 1538-1553.

Leydesdorff, L., \& Rafols, I. (2011). Local emergence and global diffusion of research technologies: An exploration of patterns of network formation. Journal of the American Society for Information Science and Technology, 62(5), 846-860.

Leydesdorff, L., \& Sun, Y. (2009). National and international dimensions of the Triple Helix in Japan: University-industry-government versus international coauthorship relations. Journal of the American Society for Information Science and Technology, 60(4), 778-788.

Link, A. N. (2015). Capturing knowledge: Private gains and public gains from university research partnerships. Foundations and Trends ${ }^{\circledR}$ in Entrepreneurship, 11(2), 139-206.

Lockett, A., \& Wright, M. (2005). Resources, capabilities, risk capital and the creation of university spin-out companies. Research Policy, 34(7), 1043-1057.

Lombardi, P., Giordano, S., Farouh, H., \& Yousef, W. (2012). Modelling the smart city performance. Innovation: The European Journal of Social Science Research, 25(2, SI), 137-149. 
Maietta, O. W. (2015). Determinants of university-firm R\&D collaboration and its impact on innovation: A perspective from a low-tech industry. Research Policy, 44(7), 1341-1359.

Mansfield, E. (1991). Academic research and industrial innovation. Research Policy, 20(1), 1-12.

Mansfield, E. (1995). Academic research underlying industrial innovations: Sources, characteristics, and financing. The Review of Economics and Statistics, 77(1), 55.

Marcovich, A., \& Shinn, T. (2011). From the Triple Helix to a quadruple helix? The case of dip-pen nanolithography. Minerva, 49(2), 175-190.

Mathies, C., \& Slaughter, S. (2013). University trustees as channels between academe and industry: Toward an understanding of the executive science network. Research Policy, 42(6-7), 1286-1300.

McMullen, J. S., \& Dimov, D. (2013). Time and the entrepreneurial journey: The problems and promise of studying entrepreneurship as a process. Journal of Management Studies, 50(8), 1481-1512.

Meyer, M. (2003). Academic entrepreneurs or entrepreneurial academics? Research-based ventures and public support mechanisms. R\&D Management, 33(2), 107-115.

Meyer, M., Grant, K., Morlacchi, P., \& Weckowska, D. (2014). Triple Helix indicators as an emergent area of enquiry: A bibliometric perspective. Scientometrics, 99(1), 151-174.

Minguillo, D., Tijssen, R., \& Thelwall, M. (2015). Do science parks promote research and technology? A scientometric analysis of the UK. Scientometrics, 102(1), 701-725.

Morandi, V. (2013). The management of industry-university joint research projects: How do partners coordinate and control R\&D activities? The Journal of Technology Transfer, 38(2), 69-92.

Mora-Valentin, E. M., Montoro-Sanchez, A., \& Guerras-Martin, L. A. (2004). Determining factors in the success of R\&D cooperative agreements between firms and research organizations. Research Policy, 33, 17-40.

Mowery, D. C., Nelson, R. R., Sampat, B. N., \& Ziedonis, A. A. (2001). The growth of patenting and licensing by U.S. universities: An assessment of the effects of the Bayh-Dole act of 1980. Research Policy, 30(1), 99-119.

Muscio, A., \& Pozzali, A. (2013). The effects of cognitive distance in university-industry collaborations: Some evidence from Italian universities. The Journal of Technology Transfer, 38(4), 486-508.

O'Shea, R. P., Allen, T. J., Chevalier, A., \& Roche, F. (2005). Entrepreneurial orientation, technology transfer and spinoff performance of US universities. Research Policy, 34(7), 994-1009.

Park, H. W., Hong, H. D., \& Leydesdorff, L. (2005). A comparison of the knowledge-based innovation systems in the economies of South Korea and the Netherlands using Triple Helix indicators. Scientometrics, 65(1), 3-27.

Perkmann, M., Neely, A., \& Walsh, K. (2011). How should firms evaluate success in university-industry alliances? A performance measurement system. $R \& D$ Management, 41(2, SI), 202-216.

Perkmann, M., Tartari, V., McKelvey, M., Autio, E., Broström, A., D’Este, P., et al. (2013). Academic engagement and commercialisation: A review of the literature on university-industry relations. $R e$ search Policy, 42(2), 423-442.

Perkmann, M., \& Walsh, K. (2007). University-industry relationships and open innovation: Towards a research agenda. International Journal of Management Reviews, 9(4), 259-280.

Petruzzelli, A. M. (2011). The impact of technological relatedness, prior ties, and geographical distance on university-industry collaborations: A joint-patent analysis. Technovation, 31(7), 309-319.

Plewa, C., Korff, N., Baaken, T., \& Macpherson, G. (2013a). University-industry linkage evolution: An empirical investigation of relational success factors. R\&D Management, 43(4), 365-380.

Plewa, C., Korff, N., Johnson, C., Macpherson, G., Baaken, T., \& Rampersad, G. C. (2013b). The evolution of university-industry linkages-A framework. Journal of Engineering and Technology Management, $30(1), 21-44$.

Ponds, R., Oort, F. V., \& Frenken, K. (2010). Innovation, spillovers and university-industry collaboration: An extended knowledge production function approach. Journal of Economic Geography, 10(2), 231-255.

Presutti, M., Boari, C., Majocchi, A., \& Molina-Morales, X. (2017). Distance to customers, absorptive capacity, and innovation in high-tech firms: The dark face of geographical proximity. Journal of Small Business Management. https://doi.org/10.1111/jsbm.12323.

Qi Dong, J., McCarthy, K. J., \& Schoenmakers, W. W. M. E. (2017). How central is too central? Organizing interorganizational collaboration networks for breakthrough innovation. Journal of Product Innovation Management, 34(4), 526-542.

Rasmussen, E., \& Wright, M. (2015). How can universities facilitate academic spin-offs? An entrepreneurial competency perspective. The Journal of Technology Transfer, 40(5), 782-799.

Rizzo, U. (2015). Why do scientists create academic spin-offs? The influence of the context. The Journal of Technology Transfer, 40(2), 198-226. 
Robin, S., \& Schubert, T. (2013). Cooperation with public research institutions and success in innovation: Evidence from France and Germany. Research Policy, 42(1), 149-166.

Rosenbusch, N., Brinckmann, J., \& Bausch, A. (2011). Is innovation always beneficial? A meta-analysis of the relationship between innovation and performance in SMEs. Journal of Business Venturing, 26(4), $441-457$.

Salter, A. J., \& Martin, B. R. (2001). The economic benefits of publicly funded basic research: A critical review. Research Policy, 30(3), 509-532.

Santoro, M. D., \& Chakrabarti, A. K. (2002). Firm size and technology centrality in industry-university interactions. Research Policy, 31(7), 1163-1180.

Schartinger, D., Rammer, C., Fischer, M. M., \& Frohlich, J. (2002). Knowledge interactions between universities and industry in Austria: Sectoral patterns and determinants. Research Policy, 31(3), 303-328.

Schmidt, F. L., \& Hunter, J. (2004). General mental ability in the world of work: Occupational attainment and job performance. Journal of Personality and Social Psychology, 86(1), 162-173.

Shah, S. K., \& Pahnke, E. C. (2014). Parting the ivory curtain: Understanding how universities support a diverse set of startups. The Journal of Technology Transfer, 39(5), 780-792.

Siegel, D. S., Waldman, D., \& Link, A. (2003). Assessing the impact of organizational practices on the relative productivity of university technology transfer offices: An exploratory study. Research Policy, 32(1), 27-48.

Siegel, D. S., \& Wright, M. (2015). Academic entrepreneurship: Time for a rethink? British Journal of Management, 26(4), 582-595.

Simeth, M., \& Raffo, J. D. (2013). What makes companies pursue an open science strategy? Research Policy, 42(9), 1531-1543.

Small, H. (1973). Co-citation in the scientific literature: A new measure of the relationship between two documents. Journal of the American Society for Information Science, 24(4), 265-269.

Soh, P.-H., \& Subramanian, A. M. (2014). When do firms benefit from university-industry R\&D collaborations? The implications of firm R\&D focus on scientific research and technological recombination. Journal of Business Venturing, 29(6), 807-821.

Svensson, P., Klofsten, M., \& Etzkowitz, H. (2012). An entrepreneurial university strategy for renewing a declining industrial city: The Norrkoping way. European Planning Studies, 20(4), 505-525.

Tartari, V., \& Breschi, S. (2012). Set them free: Scientists' evaluations of the benefits and costs of university-industry research collaboration. Industrial and Corporate Change, 21(5), 1117-1147.

Tartari, V., Perkmann, M., \& Salter, A. (2014). In good company: The influence of peers on industry engagement by academic scientists. Research Policy, 43(7), 1189-1203.

Teixeira, A. A. C., \& Mota, L. (2012). A bibliometric portrait of the evolution, scientific roots and influence of the literature on university-industry links. Scientometrics, 93(3), 719-743.

Tether, B. S., \& Tajar, A. (2008). Beyond industry-university links: Sourcing knowledge for innovation from consultants, private research organisations and the public science-base. Research Policy, 37(6-7), 1079-1095.

Thursby, J. G., \& Thursby, M. C. (2002). Who is selling the ivory tower? Sources of growth in university licensing. Management Science, 48(1), 90-104.

Torres, A., Dutrenit, G., Sampedro, J. L., \& Becerra, N. (2011). What are the factors driving universityindustry linkages in latecomer firms: Evidence from Mexico. Science and Public Policy, 38(1, SI), $31-42$.

Treibich, T., Konrad, K., \& Truffer, B. (2013). A dynamic view on interactions between academic spin-offs and their parent organizations. Technovation, 33(12), 450-462.

Uy, M. A., Foo, M. D., \& Aguinis, H. (2010). Using experience sampling methodology to advance entrepreneurship theory and research. Organizational Research Methods, 13(1), 31-54.

van der Valk, T., Chappin, M. M. H., \& Gijsbers, G. W. (2011). Evaluating innovation networks in emerging technologies. Technological Forecasting and Social Change, 78(1), 25-39.

van Eck, N. J., \& Waltman, L. (2007). VOS: A new method for visualizing similarities between objects (pp. 299-306). Berlin: Springer.

van Eck, N. J., \& Waltman, L. (2009). How to normalize cooccurrence data? An analysis of some wellknown similarity measures. Journal of the American Society for Information Science and Technology, $60(8), 1635-1651$.

van Eck, N. J., \& Waltman, L. (2010). Software survey: VOSviewer, a computer program for bibliometric mapping. Scientometrics, 84(2), 523-538.

Van Looy, B., Landoni, P., Callaert, J., van Pottelsberghe, B., Sapsalis, E., \& Debackere, K. (2011). Entrepreneurial effectiveness of European universities: An empirical assessment of antecedents and trade-offs. Research Policy, 40(4), 553-564. 
Van Looy, B., Ranga, M., Callaert, J., Debackere, K., \& Zimmermann, E. (2004). Combining entrepreneurial and scientific performance in academia: Towards a compounded and reciprocal Mattheweffect? Research Policy, 33(3), 425-441.

Villani, E., Rasmussen, E., \& Grimaldi, R. (2017). How intermediary organizations facilitate universityindustry technology transfer: A proximity approach. Technological Forecasting and Social Change, 114, 86-102.

von Raesfeld, A., Geurts, P., Jansen, M., Boshuizen, J., \& Luttge, R. (2012). Influence of partner diversity on collaborative public R\&D project outcomes: A study of application and commercialization of nanotechnologies in the Netherlands. Technovation, 32(3-4, SI), 227-233.

Waltman, L., van Eck, N. J., \& Noyons, E. C. M. (2010). A unified approach to mapping and clustering of bibliometric networks. Journal of Informetrics, 4(4), 629-635.

Wang, Y., Yu, Y., Chen, M., Zhang, X., Wiedmann, H., \& Feng, X. (2015). Simulating industry: A holistic approach for bridging the gap between engineering education and industry. Part I: A conceptual framework and methodology. International Journal of Engineering Education, 31(1, A), 165-173.

Williamson, O. E. (1991). Comparative economic organization: The analysis of discrete structural alternatives. Administrative Science Quarterly, 36(2), 269.

Wirsich, A., Kock, A., Strumann, C., \& Schultz, C. (2016). Effects of university-industry collaboration on technological newness of firms. Journal of Product Innovation Management, 33(6), 708-725.

Wright, M., Clarysse, B., Lockett, A., \& Knockaert, M. (2008). Mid-range universities' linkages with industry: Knowledge types and the role of intermediaries. Research Policy, 37(8), 1205-1223.

Wright, M., Siegel, D. S., \& Mustar, P. (2017). An emerging ecosystem for student start-ups. The Journal of Technology Transfer, 42(4), 909-922.

Zahra, S. A., \& George, G. (2002). Absorptive capacity: A review, reconceptualization, and extension. Academy of Management Review, 27(2), 185-203.

Zalewska-Kurek, K., Egedova, K., Peter, A. T. M., \& Roosendaal, H. E. (2016). Knowledge transfer activities of scientists in nanotechnology. The Journal of Technology Transfer. https://doi.org/10.1007/ s10961-016-9467-6.

Zhang, J. (2009). The performance of university spin-offs: An exploratory analysis using venture capital data. The Journal of Technology Transfer, 34(3), 255-285.

Zucker, L. G., \& Darby, M. R. (1996). Star scientists and institutional transformation: Patterns of invention and innovation in the formation of the biotechnology industry. Proceedings of the National Academy of Sciences, 93(23), 12709-12716. 